\title{
Deep Crustal Structure of the North-West African Margin from Combined Wide-angle and Reflection Seismic Data (MIRROR Seismic Survey)
}

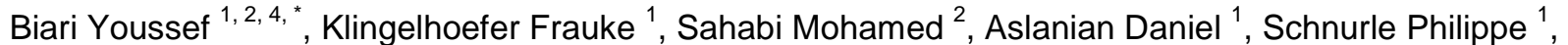 \\ Berglar K. ${ }^{3}$, Moulin Maryline ${ }^{1}$, Mehdi K. ${ }^{2}$, Graindorge David ${ }^{4}$, Evain Mikael ${ }^{1}$, \\ Benabdellouahed Massinissa ${ }^{1}$, Reichert Christian ${ }^{3}$
}

\footnotetext{
1 Ifremer, Dept. Marine Geosciences, ZI de la Pointe du Diable, CS10070, 29280 Plouzané, France

${ }^{2}$ Université Chouaïb Doukkali - Faculté Des Sciences, Laboratoire Géosciences marines et Sciences des sols - URAC 45, BP 20, 24000 El Jadida, Morocco

${ }^{3}$ Bundesanstalt fuer Geowissenschaften und Rohstoffe (BGR), Geozentrum Hannover, Stilleweg 2, 30655 Hannover, Germany

${ }^{4}$ UMR 6538 Domaines océaniques, IUEM, Place Nicolas Copernic, 29280 Plouzané, France

* Corresponding author : Youssef Biari, Tel.: + 33650222153 (mobile) ; + 33298224028 (office) ; fax: + 33298224549 ; email address : youssef.biari@ifremer.fr
}

\begin{abstract}
:
The structure of the Moroccan and Nova Scotia conjugate rifted margins is of key importance for understanding the Mesozoic break-up and evolution of the northern central Atlantic Ocean basin. Seven combined multichannel reflection (MCS) and wide-angle seismic (OBS) data profiles were acquired along the Atlantic Moroccan margin between the latitudes of $31.5^{\circ}$ and $33^{\circ} \mathrm{N}$ during the MIRROR seismic survey in 2011, in order to image the transition from continental to oceanic crust, to study the variation in crustal structure and to characterize the crust under the West African Coast Magnetic Anomaly (WACMA). The data were modeled using a forward modeling approach. The final models image crustal thinning from $36 \mathrm{~km}$ thickness below the continent to approximately $8 \mathrm{~km}$ in the oceanic domain. A $100 \mathrm{~km}$ wide zone characterized by rough basement topography and high seismic velocities up to $7.4 \mathrm{~km} / \mathrm{s}$ in the lower crust is observed westward of the West African Coast Magnetic Anomaly. No basin underlain by continental crust has been imaged in this region, as has been identified north of our study area. Comparison to the conjugate Nova Scotian margin shows a similar continental crustal thickness and layer geometry, and the existence of exhumed and serpentinized upper mantle material on the Canadian side only. The oceanic crustal thickness is lower on the Canadian margin.
\end{abstract}




\section{Highlights}

- Wide-angle seismic data modeling reveils the deep structure of the Moroccan continental margin Continental crustal thickness decreases from $37 \mathrm{~km}$ to about $10 \mathrm{~km}$ - High seismic velocities up to 7.4 $\mathrm{km} / \mathrm{s}$ in the lower oceanic crust are observed Mantle velocities are 8.0 to $8.2 \mathrm{~km} / \mathrm{s}$, excluding extensive serpentinisation during breakup - No extrusive volcanic products such as sills, seaward dipping reflectors or underplate have been imaged

Keywords : Moroccan continental margin, wide-angle seismic modeling, deep crustal structure 


\section{Introduction}

Combined wide-angle and deep reflection seismic data provide images of the deep crustal structure of a continental margin as well as the overlying sedimentary layers. These data represent a key to understand the geometry and mechanism of rifting, the nature of the ocean-continent transition and the physical properties of the crust. Different models have been proposed to describe the processes and the mechanisms of lithospheric thinning involving passive or active rifting (e.g. Sengör and Burke, 1978), pure shear (McKenzie, 1978) or simple shear (Wernicke, 1985), or a mixture of both types (e.g. Lister and Davis, 1989; Boillot et al., 1995; Whitmarsh et al., 2001). The diversity of passive continental margins (magmatic or non-magmatic, symmetric or asymmetric, associated with a salt basin or not, etc.) may be related to these different processes, as well as to tectonic inheritance (Aslanian and Moulin, 2013).

The central Atlantic passive margin of Nova Scotia and Morocco results from the break up of the Pangean supercontinent. While the Nova Scotia margin has been subject to numerous marine geophysical studies (e.g. Funck et al., 2004; Wu et al., 2006), the conjugate African segment remains fairly unknown, except for the northernmost segment ((Holik et al., 1991a); Contrucci et al., 2004; Jaffal et al., 2009; Klingelhoefer et al., 2009).

In this study, the results of a wide-angle seismic experiment called MIRROR (The deep Moroccan margin as Imaged by Reflection and Refraction seismic data: Ocean-continent boundary of a Rifted margin) located in the central NW African segment between $31.5^{\circ}$ and $33^{\circ} \mathrm{N}$, seaward of the Moroccan Meseta (Figure 1) will be presented. During the MIRROR cruise (2011), a joint project between Ifremer, the Universities of Brest, El Jadida and Lisbon and the German BGR (Bundesanstalt fuer Geowissenschaften und Rohstoffe), seven combined wide-angle and multi-channel seismic profiles were acquired on the central Moroccan margin offshore Safi. The main objectives of this project were to image the deep crustal structure of this segment of the margin, to characterize its ocean continent boundary and to constrain the amount of volcanic products in this region. 


\section{Geodynamic \& Geological setting}

Rifting in the central Atlantic Ocean occurred in a single phase, starting around 180-200 Ma, at the Triassic-Early Jurassic (Lias) boundary (e.g (Le Roy and Piqué, 2001; Michard et al., 2008). Rifting coincided with high aerial volcanic activity at the Central Atlantic Magmatic Province (CAMP) (Hames et al., 2000, 2003; McHone, 2000). Magmatism is represented by dikes, sills and basaltic lava flows developed on both Atlantic margins (Olsen, 1999). CAMP magmatic events are dated between 197203 Ma (Knight et al., 2004; Marzoli et al., 2004; Hames et al, 2000).

Two magnetic anomalies named East Coast Magnetic Anomaly (ECMA) and the West African Magnetic Anomaly (WACMA) bound the oceanic domain at the transition between the continent and the oldest oceanic crust. Therefore, their position allows us to reconstruct the geometry of the plates at the initial opening of the Atlantic Ocean (Sahabi et al., 2004).

The East Coast Magnetic Anomaly (ECMA) is a strong and continuous magnetic anomaly, extending from Georgia to Nova Scotia, (Drake et al., 1959; Keller et al., 1954). This positive magnetic anomaly (ECMA), with amplitudes ranging from 200-300 nT, varies in character along the margin. Off Nova Scotia, this anomaly becomes progressively weaker to the north and decrease in amplitude (180 nT) until its disappearance in the northeastern segment of the Nova-Scotia margin (e.g Dehler, 2011; Funck et al., 2004). Located near the continental shelf, the ECMA can be used to mark the oceancontinent transition zone. Some layers of volcanic seaward dipping reflectors (SDR's) have been imaged in the Baltimore Basin (Hinz, 1981; Austin et al., 1990; Holbrook and Kelemen, 1993; Talwani et al., 1995) an observation, which indicates volcanic activity during rifting in that area. However, SDR's are absent along the northern part of the American central Atlantic margin (Funck et al., 2003; Funck et al., 2004). Seaward of the ECMA a second magnetic anomaly was identified, called the Blake Spur Magnetic Anomaly (BSMA) (Hinz, 1981; Austin et al., 1990; Sheridan et al., 1993; Holbrook et al., 1994; Talwani et al., 1995). The DSDP drill site 534 east of the BSMA reached oceanic crust and demonstrated the magnetic anomaly at this location to be Callovien (165Ma) (Gradstein et al., 2004). 
On the African side a magnetic anomaly similar to the ECMA, called the West African Coast Magnetic Anomaly (WACMA) or S1 anomaly can be traced from the northern Moroccan salt basin down to Senegal in the south. However, along the entire margin its amplitude is lower of than that of the ECMA. The WACMA can be considered as the conjugate of the ECMA (Sahabi et al., 2004), and was used to identify the continent-ocean transition zone at the African margin (Hinz et al., 1982; Roeser, 1982; Roeser et al., 2002; Sahabi, 2004; Sahabi et al., 2004). However, no SDR's have yet been imaged on the African margin. South of this region, the WACMA is located very close to the continent.

The original reconstruction of opening of the Atlantic was based on shorelines only (Bullard et al., 1965). Subsequently, the work of (Olivet et al., 1984) was additionally based on the position of magnetic anomalies and all conjugate geological structures, such as fracture zones and mountain ranges.

The onset of sea floor spreading and the formation of the first oceanic crust remains disputed and may have been as late as $175 \mathrm{Ma}$ (Klitgord and Schouten, 1986), however, a recent study based on the correlation of magnetic anomalies, salt distribution and seismic data from both margins (Sahabi et al., 2004) proposed the oldest oceanic crust to be of Sinemurian times (195 Ma), 25 My older than that of previously published work.

Located between $36^{\circ} \mathrm{N}$ and $21^{\circ} \mathrm{N}$, the Moroccan margin can be subdivided into several basins:

On land in our study region, the Triassic-Liassic basins of Doukkala-Abda and Essaouira Agadir (Figure 1 B), developed above Hercynian basement, and are structured by a set of horst and grabens (Le Roy, 1997; Le Roy et al., 1997). They can be identified by the presence of salt deposits on land (Essaouira basins) and at sea (Seine abyssal plain) (Pautot and Le Pichon, 1970). Reflection seismic data (Hinz et al., 1982; Sahabi et al., 2004; Jaffal et al., 2009), indicated that the area of these salt deposits is limited roughly between $35^{\circ} \mathrm{N}$ and the latitude of Fuerte-Ventura (Sahabi et al., 2004) (Figure $1 \mathrm{~B}$ ). In this region the hinge line is located at the seaward side of the wide basin, in the area, where the 
basement depth increases in response to thinning of the continental crust. Farther south at the Tarfaya-Laâyoun basins, Sahabi, 2004 based on a tectonic map of Choubert et al., 1968 locate the hinge line on land. During Middle and Upper Jurassic, carbonate platforms developed in this region (Jansa, 1981; Hinz et al., 1982).

\section{Previous work}

The SISMAR cruise presented the first modern wide-angle seismic study on the Moroccan Atlantic margin offshore El Jadida (Contrucci et al., 2004; Maillard et al., 2006; Jaffal et al., 2009), located at the junction between two plates boundaries: that of the Atlantic break-up and the strike-slip secondorder boundary (Olivet et al., 1984) of the South Grand Banks - Gloria Fracture Zone, which accommodated the movement of the Iberian plate. Based on forward modeling of the wide-angle seismic data Contrucci et al. (2004) propose a crustal thickness of $35 \mathrm{~km}$ for the unthinned continental crust and $7 \mathrm{~km}$ for the oceanic crust. The zone of crustal thinning (the necking zone) has a width of $150 \mathrm{~km}$. A $200 \mathrm{~km}$ wide and up to $6-7 \mathrm{~km}$ thick sedimentary basin is located at the foot of the continental slope. This basin is underlain by thinned continental crust. No high velocities, which may correspond to serpentinized upper mantle material were modeled. The oceanic crust west of magnetic M25 is about $8 \mathrm{~km}$ thick, but may be over thickened due to recent tectonic inversion and compression.

Farther south between $30^{\circ} \mathrm{N}$ and $35^{\circ} \mathrm{N}$, some high velocities in the lower part of the oceanic crust were modeled based on sonobuoy data (Holik et al., 1991). The authors proposed that these high velocities could be explained by the existence of magmatic underplating that originated from the passage of the Canary hotspot through the region.

Results from the DAKHLA cruise margin located south of our study show that unthinned continental crust here is about $27 \mathrm{~km}$ thick, thinning to $10 \mathrm{~km}$ at the continental slope (Klingelhoefer et al., 2009; Labails et al., 2009). The oceanic crust has a thickness of $7 \mathrm{~km}$ with relatively high velocities in the lower crust from the continental slope up to the magnetic anomaly M25. West of the magnetic 
anomaly M25 lower crustal velocities are normal for oceanic crust. This change of lower crustal velocities may be related to a change in oceanic spreading rate.

Based on industrial seismic and potential field data, Tari and Molnar, (2005) propose the existence of a high-relief accommodation zone at the Tafelney plateau, with the northern Moroccan margin acting as upper plate margin and the southern Moroccan margin representing a lower plate margin. More recently, Sibuet et al., (2012) proposed a new interpretation of the WACMA anomaly including two ridge jumps, the first jump leading to the existence of a part of the Canadian plate on the Moroccan side and a second jump leaving most of the exhumed upper mantle material on the Canadian side.

\section{Seismic Experiment}

\subsection{Data Acquisition}

During the MIRROR survey multi-channel reflection seismic (MCS) and wide-angle seismic (WAS) profiles were acquired along with magnetic, bathymetric and high resolution seismic data. The seismic experiment consisted of two profiles perpendicular to the margin, and five profiles parallel to the margin. Conducted onboard R/V L'Atalante, all profiles were acquired using a tuned airgun array of $7591 \mathrm{in}^{3}$ and 42 ocean-bottom seismometers (OBS), equipped with a 3-component geophone and a hydrophone (Auffret et al., 2004). One profile (MI-01) was extended $150 \mathrm{~km}$ on land by 15 landstations (Figure 2) from the University of Lisbon.

The MCS data were acquired simultaneously with the wide-angle seismic data and consisted of recording 13,387 shots along 8 profiles with a complete length of $1206 \mathrm{~km}$. The airgun array was tuned to the first peak and fired at a constant time interval of 60s leading to an approximate trace spacing of $150 \mathrm{~m}$. Only profile MI-08 covering the landward end of profile MI-01 was acquired using an airgun source of lower volume $\left(3609 \mathrm{in}^{3}\right.$ ) in order to provide a smaller shot interval of $25 \mathrm{~s}$ ( $65 \mathrm{~m}$ 
interval). All MCS profiles were recorded using a $4.5 \mathrm{~km}$ digital streamer composed of 360 channels at a $12.5 \mathrm{~m}$ interval spacing.

\subsection{Data quality and processing of the multi-channel seismic data}

The processing sequence was composed of external and internal mutes, band pass filtering, NMO (Normal Move Out) and DMO (Dip Move Out) corrections. Depending on the structural complexity of each profile, velocity analysis was performed every 500, 250 or 125 common mid-points (CMP). The suppression or reduction of multiple energy was done mainly with the Surface Related Multiple Estimation (SRME) module. Multiple estimates were calculated and then adaptively subtracted from the data. In order to reduce ringing within the dataset and to shorten the seismic wavelet, an ensemble predictive deconvolution was applied in the CDP domain averaging the operator design over 11 traces. Operator length was $256 \mathrm{~ms}$, prediction distance of $48 \mathrm{~ms}$ and the white noise level 0.1. Design gates were picked relative to the water bottom shortly before the first break up to 3 seconds later.

The last processing step included stack, filtering and migration. On all profiles the sedimentary layers and the top of the basement are well imaged in the reflection seismic section. Intercrustal reflections and Moho reflections are rare.

\subsection{Data quality and pre-preprocessing of the wide-angle seismic data}

Pre-processing of the OBS data included calculation of the clock-drift corrections. The individual time drifts were between 0 and $30 \mathrm{~ms}$ per day with a mean of $10.25 \mathrm{~ms}$. Instrument locations were corrected for drift from the deployment position during their descent to the seafloor using the direct water wave arrival. Instruments in water depth less than $100 \mathrm{~m}$ were not corrected as the expected drift is small. Furthermore, instruments that recorded no close shots were not corrected, if no direct water wave arrival could be picked as a first arrival. The drift of the instruments never exceeded 100 $m$, even in deep water. In order to increase the signal-to-noise ratio and to improve the far-offset 
arrivals, band-pass filtering was applied to remove low and very high frequency noise. A deconvolution and automatic gain control were applied to all OBS data (Figure 3). However, picking was done on unprocessed data when possible, and the processed data were used only in regions of high ambient noise.

Along both profiles perpendicular to the margin ( $\mathrm{MI}-01$ and $\mathrm{MI}-02)$, data quality on both hydrophone and geophone channels is high and increases westward, mainly due to the absence of salt domes and basement blocks in these regions (Figure 3 and 4). The seismic sections show clear arrivals from sedimentary layers (Ps1, Ps2, and Ps3) for offsets $>6 \mathrm{~km}$. Crustal arrivals are easily identifiable and mark the presence of two distinct layers (Pc1, Pc2) along all profiles. These phases can be identified at offsets between 15 and up to $50 \mathrm{~km}$. Useful arrivals from the Moho (PmP) and upper mantle (Pn) have been identified on most OBS sections. PmP arrivals are present in the data between offsets of 25-50 km. Pn phase is identifiable for offsets $>50 \mathrm{~km}$, some weak energy of Pn arrivals can be traced to offsets of up to $100 \mathrm{~km}$ in the marine instruments record sections and up to $350 \mathrm{~km}$ on the land station record sections.

The data quality on profiles parallel to the margin (MI-03, MI-04, MI-05, MI-06 and MI-07) is comparable to those perpendiculars to the margin (Figure 3). First arrivals from the profile MI-03 are characterized by large undulations in the crustal arrivals, mainly due to the steep basement relief and the presence of salt. Reflections from the upper mantle could be identified on 10 out of 13 record sections, but turning waves from the upper mantle are scarce and originate mostly from shots or OBS located at the southern end of the profile. On profiles $\mathrm{MI}-04$ and $\mathrm{MI}-05$, the undulations smooth out and disappear with increasing distance from the continental slope. Here, arrivals from the upper mantle are more easily discernible. Finally, the OBS sections from profiles MI-06 and MI-07 are of very good quality and image clear arrivals from the crust, the crust-mantle boundary and the upper mantle. 
All land-stations recorded data of excellent quality, except the one closest to the sea, which had a high ambient noise level (Figure 4). Several of the land-stations recorded shots from nearly the complete profile with offsets up to $350 \mathrm{~km}$. Due to the absence of shots on land, only crustal and upper mantle arrivals could be picked in the land-stations data.

\section{Wide-angle seismic data modeling}

Travel-times for first and secondary arrivals were picked in the complete data set without applying a filter were possible. Only noisy data sections and large offsets were picked using frequency filtering. Travel time picks were modeled using the 2-D ray tracing "Rayinvr" software (Zelt and Smith, 1992). The main goal was to construct detailed velocity models of the crust and uppermost mantle by applying a top-down layer-stripping approach. The $2 \mathrm{D}$ velocity models are composed of a sequence of layers; each layer is defined by depth and velocity nodes.

Phases observed on all record sections include the water wave arrival, two or three high-amplitude sedimentary arrivals, as well as upper and lower crustal arrivals. Most record sections include deeper arrivals such as strong reflections from the Moho and weaker turning waves from the upper mantle. Land station record sections show crustal and upper mantle arrivals only, as no reverse shots were carried out on land. A very late high-amplitude reflection from a reflector situated in the mantle was identified in land station data only.

The geometry of the sedimentary layers and basement were picked from the reflection seismic data and converted to depth using velocities from the OBS data. Only those layers identified on both the reflection and wide-angle seismic data as distinct arrivals were included into the models to avoid over-parameterization of the inversion, so some additional layering in the sedimentary section is imaged by the reflection seismic data (Figure 11 \& 12).

The seafloor layer was taken from the bathymetric data.The water velocity used for modeling was kept a constant $1.5 \mathrm{~km} / \mathrm{s}$. The depth and velocities of the crustal layers and the upper mantle were 
modeled from the OBS data only. The final velocity models consist of 3 sedimentary, 2 crustal and the upper mantle layer, except profile $\mathrm{MI}-01$, where an additional crustal layer was introduced for modeling of the onland part of the model. The thickness and depth of this additional interface are constrained by reflections identified in the landstation data (Figure 4). A very late arriving reflection originating from the deep mantle was also picked from the landstation data and was subsequently modelled as a floating reflector in the mantle layer (Figure 4).

\subsection{Error Analyses}

A total of 73,186 travel times were picked ( 7213 on land station data and 65,973 on OBS data).

The root mean square (rms) error gives the misfit between predicted arrival times and travel time picks and the chi ${ }^{2}$-value additionally takes the picking error into account. Picking errors were assigned values between $30 \mathrm{~ms}$ for the water and $120 \mathrm{~ms}$ for upper mantle arrivals. For low amplitude far offset arrivals probably the first peak cannot be identified in the data set and the more energetic and lower frequency first bubble pulse is picked. Therefore, a larger picking error was assigned to these phases. The number of picks, the picking error, and the rms misfit for each phase of all the velocity models are summarized in table 01 . All profiles give acceptable final rms errors, between 84 to $137 \mathrm{~ms}$ for the complete profiles and 30 to $166 \mathrm{~ms}$ for individual phases. The arrivals from the deepest layers and some secondary arrivals produce the highest travel-time errors.

The resolution factor is calculated using the number of rays passing through parts of the velocity models, constrained by one single velocity node normalized to the number of rays passing the same layer (Zelt and Smith, 1992). Therefore, this test depends on the number of nodes in the model, and the resolution parameter will be high if a layer is modeled using one single velocity gradient and lower when lateral velocity changes are included. Resolution therefore indicates if an unnecessarily large amount of velocity nodes was included into the velocity mode thereby increasing the risk that features unconstrained by the data are being modelled. Nodes with values greater than 0.5 are considered well resolved. Only few parts of the profiles are marked by a resolution less than 0.5 , 
which is considered insufficiently resolved (see red color in Figure 7). These parts correspond mostly to the extremities of the velocity models and low-velocity layer unconstrained by rays turning in this layer.

Sedimentary and the basement layers are generally well resolved along all profiles. Resolution values decrease toward the extremities of the models in layers which are defined by lateral velocity variations, such as the lower crustal layer on profiles MI-02 and MI-06 and the sedimentary layers on profile MI-04. The resolution values also decrease with depth in the upper mantle due to fewer rays penetrating into deeper parts of the models. Upper mantle velocities, however, are well resolved along all profiles. On profile MI-01, the lowermost crustal layer of the unthinned continental part of the model is less well resolved (between 0.2 and 0.5 ) than the upper crustal layers, due to lower ray coverage as shots on land are missing.

The F-test is a statistical test, used to compare two models the chi ${ }^{2}$-values and number of picks of both models in order to determine, if the models are statistically significantly different. The $95 \%$ confidence limit of significantly different variances provided by the F-test gives the upper and lower boundaries in which changing the depth or velocity of a given layer can be undertaken without significantly changing the model. Two models for which the F-test gives a lower value cannot be considered significantly different based on the data provided. Therefore, the $95 \%$ confidence limit can be used as an estimation of the depth or velocity uncertainty of a given interface (Figure $8 \mathrm{~A}$ and B). A perturbation analysis was performed by changing systematically the depth of the Moho along the complete model and the velocity of the lower crustal layer, by positive and negative values, calculating the chi ${ }^{2}$-values and applying the F-test between the perturbed and the preferred velocity model. Results from this analysis show that our preferred model allows a maximum of picks to be explained, with a minimum misfit between predicted arrival times from the modeling and travel-time picks (Figure 8). A second test was conducted systematically varying the Moho depth and lower crustal velocity along the complete length of each model, as a trade of between both parameters 
exists. The results show, that even when varying depth and lower crustal velocities simultaneously, the model error increases significantly if the depth is varied by more than $400 \mathrm{~m}$ of the velocities by more than $0.2 \mathrm{~km} / \mathrm{s}$. Additionally, it can be seen that changing the model leads to the decrease of the number of travel-time picks explained by the modeling (Figure $8 \mathrm{C}$ ).

Ray density shows well and less well constrained regions of the models (Figure 9). Generally all models are well-covered by seismic rays due to the good data quality. Ray density is slightly less underneath the continental part of profile MI-01 due to the absence of seismic shots on land. Profile $\mathrm{MI}-02$ is characterized by higher ray coverage in the center and the western part of the profile. The lower crustal layer on profile MI-03 is less well covered than on neighboring profiles due to the loss of energy in the salt layer. MI-06 and MI-07 profiles show very good ray coverage throughout all layers due to wide offsets of useful data identifiable along the record sections.

\subsection{Gravity modeling}

All final models were additionally constrained in the deeper layers and at the extremities of the profiles by gravity modeling. A predicted anomaly was calculated using the gravity module "gravmod" of the "Rayinvr" software (Zelt and Smith, 1992). The velocity models were converted to density models using the laboratory relationship of (Ludwig et al., 1970). The predicted gravity anomaly can be compared to gravity data from satellite altimetry. The fit between observed and predicted anomalies is generally good especially on the profiles perpendicular to the margin (Figure 10). For profiles $\mathrm{MI}-03$ and $\mathrm{MI}-04$, a linear trend was subtracted, which probably originates from unmodeled out-of-plane effects and possibly large wavelength density variations in the mantle which cannot be modeled using wide-angle seismic data.

\section{Results}


The interpretation and modelling of the wide angle seismic data acquired offshore the central Moroccan passive margin allows us to divide the study area between $31.5^{\circ}$ and $33^{\circ} \mathrm{N}$ into three distinct zones (Figure 2):

- Zone 1: unthinned continental crust and the necking zone which corresponds to the region where thinning of the continental crust has taken place.

- Zone2: region in which the WACMA is located.

- Zone 3: oceanic domain which can be divided into two sub-domains.

\subsection{Structure of the profiles perpendicular to the margin}

On profile MI-01 continental crust has been imaged underneath the land-stations with a thickness around $36 \mathrm{~km}$. Due the good data quality on the land-station data, three seismic phases could be used to model the unthinned continental crust as three layers (Figure 4). Crustal arrivals in the land station data could only be modeled using different velocity gradients. Some reflections on the lower to middle crustal boundary as well as on the Moho served to additionally constrain the geometry of these layers. The two upper layers are about 15 and $12 \mathrm{~km}$ thick and the lowermost layer is slightly thinner with a thickness of $\sim 9 \mathrm{~km}$. Velocities range from 5.8 to $6.4 \mathrm{~km} / \mathrm{s}, 6.5$ to $6.7 \mathrm{~km} / \mathrm{s}$, and 6.7 to $7.2 \mathrm{~km} / \mathrm{s}$, respectively (Figure 5).

Adjacent to the unthinned continental crust a necking zone characterised by shallowing of the Moho between 200 and $300 \mathrm{~km}$ model distance and deepening of the basement between 180 and $250 \mathrm{~km}$ model distance. The fact that the lowermost layer seems to pinch out here might be related to the modeling technique. Model layers once identified in the data set must span the complete model. In this area velocities at the base of the crust do not change significantly enough to constrain a pinchout of the lowermost layer. The upper and middle crustal layers are continuous throughout the profile. Seaward of $225 \mathrm{~km}$ model distance, the crustal thickness decreases from 16 to $8 \mathrm{~km}$ over a distance of $70 \mathrm{~km}$, and remains a constant $8 \mathrm{~km}$ up to the western end of the profile. The Moho 
depth is constrained to be around $37 \mathrm{~km}$ in the east, and shallows rapidly to $15 \mathrm{~km}$ between 155 and $260 \mathrm{~km}$ model distance. Based on the land-station data only, a very late arriving reflection was modeled as a floating reflector in the mantle, between 170 and $290 \mathrm{~km}$ model offset (Figure 5). It is located at a depth of 75-80 km and dips seaward.

Due to the lack of land-stations, profile MI-02 does not entirely image the unthinned continental crust (Figure 6). Nevertheless, analogous to MI-01 the crustal thickness along MI-02 changes rapidly from $\sim 16 \mathrm{~km}$ at $20 \mathrm{~km}$ model distance to only $8 \mathrm{~km}$ in the western end of the profile over a distance of $60 \mathrm{~km}$. Two crustal layers were modeled, the lowest layer appearing in MI-01 is not imaged in MI02 , again due to the shorter length of $\mathrm{MI}-02$ as compared to $\mathrm{MI}-01$. The upper layer is thinner than the lower crustal layer and thins from $\sim 10 \mathrm{~km}$ to a value of $\sim 3 \mathrm{~km}$ seaward at the western end of the profile, with velocities ranging from 5.5 to $6.4 \mathrm{~km} / \mathrm{s}$. The lower layer thickness is around $\sim 12 \mathrm{~km}$ to $\sim 5 \mathrm{~km}$ in the end of the profile, and characterized by velocities ranging from 6.6 to $7.25 \mathrm{~km} / \mathrm{s}$. The Moho depth is around $22 \mathrm{~km}$ in the east and decreases to $15 \mathrm{~km}$ between $20 \mathrm{~km}$ and $55 \mathrm{~km}$ model distance.

Seaward, the oceanic crust is characterized by a thickness of $8 \mathrm{~km}$ and a nearly constant Moho depth of $15 \mathrm{~km}$. The velocities range from $5.8-6.4 \mathrm{~km} / \mathrm{s}$ in the upper crust to $6.9-7.4 \mathrm{~km} / \mathrm{s}$ in the lower crust. Nevertheless, relatively high seismic velocities in the lower crust up to $7.25 \mathrm{~km} / \mathrm{s}$ were modeled at the eastern part of this zone. The mantle velocities are $8.00-8.30 \mathrm{~km} / \mathrm{s}$ throughout the two profiles. Based on multi-channel and wide-angle seismic data, The final velocity models of profiles MI-01 and MI-02 image three layers of sediments characterized by similar velocities (1.8 to $4.5 \mathrm{~km} / \mathrm{s}$ ), and an equal thickness of up to $5 \mathrm{~km}$ on both profiles. Between 150 and $250 \mathrm{~km}$ model distance, the sedimentary strata are perturbed by salt tectonics and some tilted fault blocks. The sediment cover gradually thins seaward to about $4 \mathrm{~km}$ at the western end of the profiles (Figure 6).

\subsection{Structure of the profiles parallel to the margin}


The two profiles closest to the coast, $\mathrm{MI}-03$ and $\mathrm{MI}-04$, are located in the salt basin. Here, crustal thickness is highly variable between 14 and $20 \mathrm{~km}$ on $\mathrm{MI}-03$ and between 10 and $17 \mathrm{~km}$ on $\mathrm{MI}-04$, due to the presence of large blocks in the basement, as for example between 30 and $60 \mathrm{~km}$ model distance on MI-03. Both profiles were modeled using two crustal layers, with slightly variable velocities but mainly between 5.80 to $6.10 \mathrm{~km} / \mathrm{s}$ and 6.70 to $7.00 \mathrm{~km} / \mathrm{s}$. Both layers are of equal thickness and relative layer thickness depends mainly on the presence of the blocks. Along both profiles, the Moho depth varies slightly decreasing towards the north. Upper mantle velocities are 8.00 to $8.30 \mathrm{~km} / \mathrm{s}$ throughout both models.

As on profiles $\mathrm{MI}-03$ and $\mathrm{MI}-04$, three sedimentary layers are imaged in profile $\mathrm{MI}-05$, with velocities between $1.9-2.0 \mathrm{~km} / \mathrm{s}$ at the top and $4.3-4.5 \mathrm{~km} / \mathrm{s}$ at the base of the sediments. The thickness of the sedimentary layers is highly variable, with a maximum thickness of $6 \mathrm{~km}$. The top of the crust has a blocky character with wider blocks ( $10 \mathrm{~km}$ length by $10 \mathrm{~km}$ width) towards the south and smaller scale roughness $(5-10 \mathrm{~km})$ in the north. Modeled velocities are between $6.0-6.5 \mathrm{~km} / \mathrm{s}$ at the upper layer and 6.8-7.2 km/s in the lower crust. The Moho depth is around $18 \mathrm{~km}$ in the south and $16 \mathrm{~km}$ in the north.

On MI-06 and MI-07, the sedimentary layer structure is continuous, with roughly the same thickness $(\sim 6 \mathrm{~km})$ along the entire models; these layers are characterized by seismic velocities between 1.9-2.1 $\mathrm{km} / \mathrm{s}$ at the top and 4.4-4.9 km/s at the bottom. Crustal thickness is 7-8 $\mathrm{km}$ for both profiles and comprises two layers, an upper layer of about 2.5-3.0 km thickness and a lower layer of approximately $5 \mathrm{~km}$. Crustal velocities are between $5.8-6.2 \mathrm{~km} / \mathrm{s}$ for the upper layer and $6.3-7.5 \mathrm{~km} / \mathrm{s}$ for the lower layer for MI-06 profile, and 5.8-6.4 km/s to $7.2 \mathrm{~km} / \mathrm{s}$ at the base of the lower layer for MI-07. The Moho depth is around $\sim 16 \mathrm{~km}$ in MI-06, slightly deeper beneath basement highs and shallow under basement lows. On MI-07, the Moho depth is around $\sim 14 \mathrm{~km}$, with smaller undulations than imaged on MI-06. Upper mantle velocities are constant between 8.0 and $8.4 \mathrm{~km} / \mathrm{s}$ (Figure 6). 


\section{Discussion}

\subsection{Nature of the crust}

In order to constrain the nature of the crust, 1D crustal velocity-depth $(\mathrm{Vz})$ profiles were extracted underneath the top of the basement at a $10 \mathrm{~km}$ interval from the final velocity models and mean curves were calculated for the different regions. These Vz graphs can be compared to compilations for typical continental crust (Christensen and Mooney, 1995), Atlantic type oceanic crust (White et al., 1992) and serpentinized upper mantle from previous work (Dean et al., 2000; Van Avendonk et al., 2006). On the base of this analysis of the final models and the Vz graphs, three distinct domains can be distinguished in the final models (A) unthinned continental domain (B) a domain of crustal thinning (necking domain), which can be divided in two subdomains one where the lowermost crustal layer thins extremely or might pinch out and a second in which crustal thinning is located mainly in the upper crustal layers and lastly (C) a domain westward of the S1 magnetic anomaly which also can be divided in two subdomains based on lower crustal velocities. The nature of each domain is discussed separately in the following sub-chapters.

\subsubsection{The unthinned continental crust}

Unthinned crust has been imaged below the land-stations on the eastern end of profile MI-01, with a maximum thickness of $36 \mathrm{~km}$. Comparison of crustal velocity-depth profiles of MI-01 to those of typical continental crust (Christensen and Mooney, 1995) reveal nearly identical seismic velocities between 6.2 and $7.0 \mathrm{~km} / \mathrm{s}$ and comparable low velocity gradients (red Vz on figure 13). Furthermore, the relative layer thickness confirms the continental origin of crust in this region. North of our study area the SISMAR survey constrained the continental crustal thickness to be $35 \mathrm{~km}$ (Contrucci et al., 2004), a value which is in good agreement with the thickness of $36 \mathrm{~km}$ obtained in this study. In both regions the data set indicates that the continental crust is divided into three distinct layers (Figure 15). 
Land seismic refraction experiments revealed that the crust of the stable continental area below the Meseta adjacent to the Moroccan Atlas is around $30 \mathrm{~km}$ (Makris et al., 1985). More recently, the seismic experiment SIMA, acquired a wide-angle seismic profile across the Moroccan Atlas and imaged a continental crust of $35-38 \mathrm{~km}$, divided into three distinct layers in the High Atlas. Crustal thickness to the north, in the Middle Atlas, was around $31 \mathrm{~km}$, only slightly thicker than the crustal thickness modeled for the MIRROR region (Ayarza et al., 2014). This indicates that the crust imaged at the eastern end of MI-01 is close to its original unthinned thickness.

However, in a teleseismic study high shear-wave velocities were modeled, suggesting that there is already mantle at the depth of $35 \mathrm{~km}$ (Palomeras et al., 2014). However, the station closest to our study area is located at a distance of $150 \mathrm{~km}$ from profile MI-01 and our study area is outside the zone proposed by the authors as region of well resolved lithosphere thickness. Modeling of several data sets, including gravity, surface heat flow and elevation shows a crustal thickness of $32 \mathrm{~km}$ in the region of our landstations increasing to $36 \mathrm{~km}$ underneath the High Atlas (Fullea et al., 2010). In this study the depth of the of the lithosphere-asthenosphere boundary is located at $90 \mathrm{~km}$ depth in this region corresponding very roughly to the depth of the deep mantle reflector modeled on profile MI01. An alternative interpretation of the origin of this deep reflector is that it may be a structure inherited from original rifting.

\subsubsection{The domain of crustal thinning}

The necking domain, in which the crustal thickness thins from $38 \mathrm{~km}$ to only $10 \mathrm{~km}$, can be divided into two subdomains, according to the velocity models and the extracted Vz profiles. Subdomain 1 is imaged only by the MI-01 profile along its on-land extension (Figure $14 \mathrm{~A}$ ). In this zone, the velocities as well as the low velocity gradients indicate that the crust is of thinned continental nature. Comparison with values from a compilation of continental crustal velocity profiles (Christensen and Mooney, 1995) confirms that crust in this domain is of thinned continental nature (Figure $14 \mathrm{~A}$ ). The

zone is characterized by an upper layer with nearly constant thickness (approximately $12 \mathrm{~km}$ 
thickness with velocities and gradient 5.8-6.2 km/s), while the thickness of lower part, formed by the middle and the lower layers, decreases from $\sim 24 \mathrm{~km}$ to $\sim 12 \mathrm{~km}$.

The subdomain 2 of the necking zone is imaged by four profiles (MI01 to MI-04; Figure 14 B and C). Here thinning occurs mainly in the upper layer (from $10 \mathrm{~km}$ to $4-5 \mathrm{~km}$ ). Along profile MI-01, the presence of tilted blocks renders the upper crustal layer thickness highly variable. The reflection seismic profiles in the region of thinned continental crust image several $20-25 \mathrm{~km}$ wide and up to $4 \mathrm{~km}$ high blocks, interpreted as tilted fault block from the initial rifting. They are overlain by salt and sedimentary layers.

Velocity-depth profiles from $\mathrm{MI}-02, \mathrm{MI}-03$ and $\mathrm{MI}-04$ extracted every $10 \mathrm{~km}$ along the profiles (Figure 14C), show that velocities of the top of the crust do not change in this domain, however the crustal thicknesses decreasing with increasing distance from the margin. As in this zone of crustal thinning minimum and maximum velocities of the crustal layers remain nearly constant, thinning leads to higher velocity gradients as the layer thickness decreases.

The region of thinned continental crust is approximately $150 \mathrm{~km}$ wide in the SISMAR study region and bordered by a $80 \mathrm{~km}$ wide basin underlain by highly thinned continental crust. It is about $120 \mathrm{~km}$ wide in the MIRROR study region. In both the SISMAR and the MIRROR datasets, the basement of the thinned continental crust is characterized by a blocky character, including three to four tilted fault blocks, often associated with salt diapirs in the sedimentary layers along the continental slope.

\subsubsection{The oceanic domain west of the WACMA magnetic anomaly}

Westward of the WACMA, Vz profiles extracted every $10 \mathrm{~km}$ along the profiles MI-1, MI-02, MI-06 and MI-07 show velocities, relative layer thicknesses and velocity gradients similar to normal oceanic crust. This is deduced by comparison to existing compilations for Atlantic type oceanic crust (White et al., 1992) which can be divided in two subdomains based on the velocity and the layer thicknesses (OC-1 and OC-2) (Figures 16 and 17). 


\section{Subdomain 1 (OC-1)}

This subdomain is imaged by four profiles (MI-01, MI-02, MI-05 and MI-06). Vz-profiles extracted from this region show higher velocities than those from typical continental crust (Christensen and Mooney, 1995) (Figure $16 \mathrm{~A}$ and $\mathrm{B})$, however, they compare well with the velocity bounds from compilations of typical oceanic crust (White et al., 1992). This subdomain presents some variations in the thickness of the upper crust ( 3 to $4 \mathrm{~km}$ ), which causes a variation of the total thickness ranging from $8 \mathrm{~km}$ to $10 \mathrm{~km}$. In this region (OC-1) the absence of salt allows good imaging of the basement reflector, which presents a rough topography in the MCS and WAS data (Figure 11 and 12). The lower layer in this subdomain (OC-1) is characterized by high velocities ranging from 7.0 to $7.4 \mathrm{~km} / \mathrm{s}$.

Several possible explanations are proposed for such elevated velocities: magmatic underplating induced by high mantle temperatures (e.g. Fowler et al., 1989; Bauer et al., 2000), continental crust intruded by sills (White et al., 2008), exhumed continental mantle material which is composed of peridotites and serpentinized by seawater (e.g. Boillot et al., 1989; Whitmarsh et al., 2001; Funck et al., 2004), thinned continental crust overlying a heterogeneous layer of intruded gabbros or intruded serpentinized peridotite (Afilhado et al., 2008), or proto-oceanic crust (Labails et al., 2009; Aslanian et al., 2009; Sibuet et al., 2012).

Volcanic margins are characterized by the existence of an underplate layer underneath the Moho, which probably consists of residual material from melting of the upper mantle This type of underplating has been proposed to exist for example at the Hatton and Edoras banks (Fowler et al., 1989; Morgan et al., 1989; Barton and White, 1997; Vogt et al., 1998) and at the Namibian continental margin (Bauer et al., 2000). It is associated with volcanic products such as sills and seaward dipping reflectors which can be imaged in the sedimentary section. In our study region, considered to be mainly non-volcanic, no extrusive volcanic products such as sills and seaward dipping reflectors have been imaged in the reflection seismic data sections. If the underplate is a discrete body, a double reflection from the top and the bottom of the mafic body should be observed 
in the data. However, this was also not observed in our dataset. So if volcanic products were added to the crust in the transitional domain they consisted most likely of smaller scale intrusions into the lower crust, rather than a discrete layer of underplate.

White et al,. (2008) suggest that the high-velocity zone in the ocean continental transition zone, imaged by wide-angle seismic data at Faroe and Hatton bank corresponds to continental crust intruded by sills. This interpretation is based on the presence of reflections from sills identified in the reflection seismic data sections which allow distinguishing between underplate and intrusions (White et al., 2008). As the velocity-depth profiles fit better to the oceanic domain and based on the absence of volcanic products in the sedimentary section as analyzed in the reflection seismic data sections, we propose that the high velocities found in our study region do not correspond to intruded continental crust.

Exhumed and serpentinized upper mantle material has been proposed to exist along continental margins formed with limited or no volcanic activity based on wide-angle seismic modelling (e.g. Chian et al., 1995; Funck et al., 2004; Van Avendonk et al., 2009). Layers of different velocities are then interpreted as mantle material serpentinized to different degrees. The base of the serpentinization front gives rise to no or only very weak reflections (Dean et al., 2000; Funck et al., 2004). Sampling of the basement in the West Iberia ocean continent transition, during the (ODP Leg 173 Shipboard Scientific Party, 1998) showed that peridotite was exposed in the ocean continent transition zone between the blocks of continental crust and the first products of oceanic accretion over a zone that appears to be tens of kilometers wide. Wide-angle seismic data from the southern Iberian Abyssal Plain show a $170 \mathrm{~km}$ wide transition zone which is interpreted to be exhumed upper mantle based on drilling results (Dean et al., 2000) (Figure 16 A zone1). The zone is divided into an upper layer, 2-4 km thick with high-velocities $(4.5-7.0 \mathrm{~km} / \mathrm{s})$, and a lower layer up to $4 \mathrm{~km}$ thick and a velocity of $7.9 \mathrm{~km} / \mathrm{s}$. The comparison of Vz profiles from this study with those from the Iberian Abyssal Plain show higher velocities in the upper layer and lower velocities in the lower layer of the crust of the Moroccan 
Margin than in the Iberian Abyssal Plain. The crustal thickness in our study region is about $3 \mathrm{~km}$ larger than in the southern Iberian Margin. At the eastern Grand Banks of Newfoundland (SCREECH 2, Figure $16 \mathrm{~A}$ zone2), the ocean-continent transition is marked by $25-\mathrm{km}$-wide zone, where seismic velocities increase gradually from $6.3 \mathrm{~km} / \mathrm{s}$ to $7.7 \mathrm{~km} / \mathrm{s}$ at $5 \mathrm{~km}$ below basement (Van Avendonk et al., 2006). The authors interpret this area as a relatively narrow zone of exhumed and serpentinized continental mantle. Comparison with Vz-profiles in domain OC-1 (Fig. 16 A zone 2) shows differences in both velocity and thickness: subdomain OC-1 shows lower velocities in the upper layer and lower layer, and a $2 \mathrm{~km}$ thicker crust than found on the eastern Grand Banks.

Seismic velocities and gradients from the OC-1 in our study region do not correspond to those of serpentinized upper mantle (Figure $16 \mathrm{~B}$ ). The presence of strong PmP reflections in our dataset contradicts the existence of a layer constituted only of serpentinized mantle here. Furthermore, the OC-1 is underlain by normal mantle with a velocity of $8.0-8.3 \mathrm{~km} / \mathrm{s}$. We therefore propose that the velocity structure in the OC-1 comprises oceanic crust 1-2 km thicker than normal oceanic crust. The slightly elevated lower crustal velocities can be explained by small remnants of peridotite surrounded by mafic intrusions and alternative interpretation is that the lower crust is slightly more mafic than elsewhere, perhaps due to the distal effects of a mantle thermal anomaly.

Northward, serpentinized upper mantle material has not been imaged by the SISMAR profiles. However, a region of thinned crust approximately $50 \mathrm{~km}$ wide marks the transition from continental crust to normal oceanic crust. This domain does not show anomalously high $p$-wave velocities typically associated with serpentinized upper mantle and typically found on non-volcanic margins (Contrucci et al., 2004). To the south, offshore Dakhla, a zone of crust of unknown composition welds continental crust to oceanic crust. The origin of this material could be exhumed serpentinized mantle material or thin oceanic crust containing high amounts of serpentinite from very slow spreading between 195 and 165 Ma (Klingelhoefer et al., 2009, Labails et al., 2009). At the base of the continental slope in both regions deep sedimentary basins are imaged. 
South of the MIRROR region a 7.1-7.3 km/s layer was observed based on refraction seismic data (Weigel et al., 1982). This layer was imaged from the shelf to the East Canary ridge over a more than $200 \mathrm{~km}$ wide region. The authors suggest that this high velocity zone was generated from high temperature mantle melts. A comparison to our dataset is difficult, as this profile was located close to the volcanic Canary Islands. However, modern seismic studies indicate, that velocities between 7.1 - $7.3 \mathrm{~km} / \mathrm{s}$ are not particularly high, so mantle temperatures might have been not elevated (Korenaga et al., 2002).

The high velocities found in crust between typical continental crust and normal oceanic crust, where interpreted to be thin oceanic crust for the Flemish Cap margin (Funck et al., 2003). Here, the ocean continent transition presents a velocity structure in good agreement with thin oceanic crust created by ultra-slow seafloor spreading with limited and/or episodic magma supply operating simultaneously with tectonic extension which provided pathways for seawater to reach and partially serpentinize the underlying uppermost mantle (Funck et al., 2003).

\section{Subdomain 2 (OC-2)}

Vz-profiles extracted from the western end of profiles MI-01 and MI-02, as well as profile MI-07 show velocities and velocity gradients in good agreement with velocity bounds for oceanic crust as compiled by White et al., 1992 (Figure $16 \mathrm{C}$ and D). The crustal thickness of 7-8 km is only slightly higher than the crustal thickness of typical oceanic crust of $7.1 \mathrm{~km}$ (White et al., 1992). The velocity gradients in the upper crust are higher than in the lower crust as is commonly found in crust of oceanic origin where the upper layer 2 is composed by basalts and the lower layer 3 is composed of gabbroic material. In this subdomain high velocities up to $7.25 \mathrm{~km} / \mathrm{s}$ have been modeled in the lower crust. These velocities are slightly higher than commonly found in oceanic crust. They can be explained by the existence of small pockets of serpentinite in the lower crust. Similarly high velocities have been found on the southern Moroccan Margin (Klingelhoefer et al., 2009) and the Mediterranean Basin (Leprêtre et al., 2013) and explained by the presence of some small amounts of 
upper mantle materiel added to the oceanic crust during its accretion. An alternative explanation could be that the crust in this domain was produced during a magma rich phase of the spreading center were more mafic volcanics were produced. Oceanic crust generated in this region at very slow spreading rates was extremely slow $(\sim 0.8 \mathrm{~cm} / \mathrm{y})$ (Labails et al., 2010), a velocity which might have inhibited sufficient mantle upwelling and mantle melting to produce a completely igneous oceanic crust. Also no volcanic products, other than the oceanic crust itself, such as seaward dipping reflectors, dikes or small seamounts, are imaged in the study area, so our preferred interpretation is that of small amounts of peridotite in the lower crust.

In the MCS data, subdomain OC-2 shows subparallel, horizontal sedimentary layers. The sediment thickness increases towards the north along MI-07 (Figure 12). The acoustic basement is characterized by a rough topography with highs and troughs each roughly $20 \mathrm{~km}$ wide, as is commonly found for oceanic crust of the Atlantic type (White et al., 1992).

Holik et al. (1991) based on sonobuoy refraction seismic data modeled a high velocity layer in the lower crust in our study region landward of magnetic anomaly M25. Seaward of the M25 anomaly, velocities in the lower crust decrease to values typical for oceanic crust, so the high-velocity zone imaged in the oceanic crust seems to be bounded by the WACMA and the M25 magnetic anomalies. The authors interpret these velocities as the result of volcanism due to a thermal anomaly in the upper mantle created by passage of the Canary hotspot in this region, starting at approximately $60 \mathrm{Ma}$.

South of the Canary Islands, an oceanic crustal thickness roughly similar to the one in the north was observed for the African margin offshore Dakhla (Klingelhoefer et al., 2009, Labails et al., 2009; Labails et al., 2010). On this segment, oceanic crust with relatively high velocities in the lower crust, characterized by a smooth basement, high lower crustal velocities (up to $7.40 \mathrm{~km} / \mathrm{s}$ ) and a roughly 0.5 to $1 \mathrm{~km}$ thicker than normal crustal is located between magnetic anomaly M25 and the oceancontinent transition zone. West of the M25 magnetic anomaly, the crust is characterized by rough 
basement, seismic velocities and crustal thickness, characteristic for Atlantic-type oceanic crust. It seems unrealistic that exhumed serpentinized upper mantle material can be present over distances of $300 \mathrm{~km}$ along profile. We propose however, that the high velocities imaged in the lower crust between the WACMA and M25 magnetic anomalies in the DAKHLA and MIRROR data sets are of a similar origin, therefore ruling out the possibility that the high velocity material imaged by the MIRROR survey results from volcanism accreted to the lower crust during the passage of the canary hotspot as well as the possibility that the high velocities represent exhumed and serpentinized upper mantle material.

For the profiles from the DAKHLA survey, the authors propose that the change from high velocity oceanic crust to normal oceanic crust at anomaly $\mathrm{M} 25$, is probably due to a change in seafloor spreading rate (Klingelhoefer et al., 2009; Labails et al., 2009; Labails et al., 2010) synchronous with a major plate reorganisation. This proposition is in good agreement with the results from this study.

Therefore, we suggest that the high velocities found in our data set are linked to slow or very slow spreading velocities during opening, which changed at the time of the M25 magnetic anomaly, as was proposed for the oceanic crust off Dakhla (Klingelhoefer et al., 2009; Labails et al., 2009; Labails et al., 2010). In this case the velocities can be explained by the existence of small pockets of serpentinite incorporated into the lower crust during accretion.

\subsection{Crustal structure at the WACMA magnetic anomaly}

The structure of the crust below the S1 anomaly has been imaged along MI-05 profile (Figure 17). The northern and the central part of the profile are located directly on the magnetic anomaly and the southern end of the profile is located in the continental domain (Figure $17 \mathrm{~A}$ ). The velocity structure modeled in the southern part is comparable to that of thinned continental crust (Christensen and Mooney, 1995) (Figure 17 D). Although velocities of the profiles from the northern end of the profile correspond well to those of oceanic crust defined by (White et al., 1992), a larger thickness than that of typical oceanic crust (White et al., 1992) (Figure $17 \mathrm{E}$ ) is found. In this zone Vz profiles show a 
structure with a difference in thickness between upper $(\sim 3 \mathrm{~km})$ and lower layers ( $\sim 6 \mathrm{~km})$. In the study area the relatively low amplitude WACMA anomaly seems to be unrelated to the existence of large amounts of either underplating or SDR's. It's origin might thus either be related to small amount of volcanic products not identifiable in the seismic data or in the composition of the crust of the transitional domain.

\subsection{Volcanism on the NW African Margin}

The lack of synrift magmatism together with the fact that no magmatic underplating has been imaged by wide-angle seismic modeling, has led to the interpretation, that the northern part of the Moroccan central Atlantic margin is a magma starved or amagmatic margin (Contrucci et al., 2004; Jaffal et al., 2009).

Similarily in this study, interpretation of the MCS data and analysis of the wide-angle seismic data has not revealed the existence of volcanic products (dikes, sills or seaward-dipping reflectors), which leads to the conclusion, that the nature of this segment of the margin (MIRROR segment) is also magma starved. Farther south on the African margin offshore Dakhla, in a similar manner no volcanic products, such as seaward-dipping reflectors, were identified (Labails et al., 2009), although magmatic activity occured on land.

However, seismic profiles acquired south of the wide-angle seismic study area during the second-leg of the MIRROR cruise between the latitudes of $30.5^{\circ}$ and $33^{\circ} \mathrm{N}$, reveal evidence that volcanic activity increases towards the south. Profiles next to the Canary Islands show clear evidence of the existence of volcanoes on the seafloor and magmatic products in the sedimentary column (Block et al., 2012). A seismic unit was identified using MCS profiles and sonobuoy deployments and interpreted as a volcanic body emplaced as the lithosphere moved northward over the Canary hotspot (Holik et al., 1991).

\section{Comparison with the conjugate Nova Scotia margin}


The continental margin of Nova Scotia presents the conjugate to the segment of the African margin discussed in this study (Sahabi et al., 2004; Labails et al,. 2009; Sibuet et al., 2012) and it is thus interesting to compare the deep structure of both margins. The Nova Scotia continental margin marks a transition from a volcanic to a nonvolcanic style of rifting. Along this segment the ECMA progressively weakens northward and disappears. During the Scotian Margin Transects (SMART) refraction seismic experiment three wide-angle seismic profiles were acquired in order to image the along-strike variation in crustal structure over the transition from a volcanic to a non-volcanic style of rifting. SMART 1, the northernmost profile images a $35 \mathrm{~km}$ thick continental crust thinning to only 3-4 $\mathrm{km}$ over a distance of $230 \mathrm{~km}$. Oceanic crust in this region is only $4 \mathrm{~km}$ thick. The ocean-continent transition zone consists of a $75 \mathrm{~km}$ wide body characterized by seismic velocities between 7.2 and 7.6 $\mathrm{km} / \mathrm{s}$, which are interpreted to be serpentinized upper mantle material (Funck et al., 2004). The neighboring the SMART 1 wide-angle seismic profile constrains very similar continental and oceanic crustal velocities and thicknesses (Luheshi et al., 2012). However, a high velocity body located at the ocean-continent transition zone is interpreted to consist of volcanic underplate, based on S-wave modeling. Farther south along SMART profile 2 a similar crustal thinning geometry was imaged, and here the ocean-continent transition contains a partially serpentinized upper mantle layer, which underlies thinned continental and very thin oceanic crust. Oceanic crust with normal thickness is observed at the seaward end of the line (Wu et al., 2006). The southernmost profile SMART 3 is located on the volcanic part of the margin and a volcanic underplate body has been imaged by the wide-angle data (Louden et al., 2010; Dehler et al., 2011). Coincident reflection seismic data show the presence of other volcanic products such as seaward dipping reflectors.

In comparison, the MIRROR profiles show a similar continental crust of $36 \mathrm{~km}$ thickness, consisting of three distinct layers. Thinning takes place over a distance $170 \mathrm{~km}$, which is about $70 \mathrm{~km}$ less than on the Canadian side on the SMART-1 profile. This is mainly due to the fact that the crust thins up to only 4-5 km thickness on the Canadian side and only to 8-9 km on the African margin side. Although high lower crustal velocities are found on both margins, they are interpreted differently, as exhumed 
and serpentinised mantle material on the SMART 1 profile, serpentinized upper mantle on the SMART 2 profile and volcanic underplate on the SMART 3 profile in the south and the OETR profile in the North. Our preferred interpretation of the MIRROR data set is that these high velocities are due to the existence small pockets of serpentinite which were introduced into the oceanic crust during very slow accretion at the onset of seafloor spreading. Ocean crust thickness ranges from only $2-3 \mathrm{~km}$ to $6 \mathrm{~km}$ on the Canadian side and 7-8 km on the Moroccan margin. This difference might be due to asymmetric spreading or to later thickening of the crust by volcanic intrusions or underplate as the Canary Hotspot moved along this part of the margin 60 Ma BP (Holik et al., 1991).

Volcanic activity along the Moroccan margin increases toward the south probably due to the influence of the Canary hotspot. This observation leads to the proposition that volcanic activity along the North-western African margin is confined to the region near to the Canary Islands, and is thus not related to the initial opening of the ocean, when little or no volcanism occurred.

\section{Conclusions}

Modeling of combined wide-angle and reflection seismic data of 7 profiles along the Moroccan Atlantic margin $\left(31.5^{\circ}-33^{\circ} \mathrm{N}\right)$ constrains the geometry of its crustal structure and its crustal nature, from the unthinned continental to the oceanic domain.

The main observations are:

- Unthinned continental crust of $36 \mathrm{~km}$ thickness is composed of three layers of 15,12 and $9 \mathrm{~km}$ thickness. The crustal thickness is similar to the northern margin and thicker than on the south Moroccan margin.

- The thinning of the continental crust occurs over distances less than $90 \mathrm{~km}$, the upper layer thins from 10 to $5 \mathrm{~km}$, and the main thinning occurs in the lower part which thins from $20 \mathrm{~km}$ to $8 \mathrm{~km}$. The data do not allow us to assess whether the lower layer disappears or if the decreasing thickness involves together middle and lower layers. 
- West of the WACMA magnetic anomaly, slightly elevated lower crustal velocities in the first oceanic subdomain OC-1 were modeled, which can be interpreted as atypical oceanic crust (or proto-oceanic crust). Their origin can be explained by small remnants of peridotite surrounded by mafic intrusive rocks.

- Oceanic subdomain OC-2 is characterized by oceanic crust of about $8 \mathrm{~km}$ thickness composed of two layers of 2 and $6 \mathrm{~km}$ thickness. Crustal thickness here is slightly higher than the crustal thickness of Atlantic-type oceanic crust. High velocities up to $7.25 \mathrm{~km} / \mathrm{s}$ have been modeled in this region. These might be related to the existence of small pockets of serpentinite in the lower crust.

No evidence for magmatism exceeding the amount needed to create oceanic crust, such as sills and seaward dipping reflectors were identified in our study region, however, volcanic activity can be imaged south of our study area, and may be related to the Canary Hotspot.

\section{Acknowledgments}

The authors wish to thank the captain and the crew of R/V L'Atalante, as well as both the OBS and the land seismic station teams. We would like to thank the Moroccan authorities for providing permission for the work on land and on sea. This work benefitted very much from discussions with Prof. Keith Louden and Dr. Helene Lau during the stay of Youssef Biari at Dalhousie University. We are very grateful for the MCS data shared with us by the BGR (Hannover). The GMT (Wessel and Smith, 1995) and Seismic Unix (Stockwell Jr., 1999; Cohen and Stockwell Jr, 2003) software packages were used in the preparation of this paper. Pre-processing and quality control of the multichannel seismic data was undertaken using the SISPEED software of Ifremer. Further processing of the MCS data was performed using the GEOCLUSTER software (CGG-Veritas). We thank native English speaking Dr. Marc-André Gutscher for correcting the English of the manuscript. 


\section{References}

Afilhado, A., Matias, L., Shiobara, H., Hirn, A., Mendes-Victor, L. and Shimamura, H.: From unthinned continent to ocean: The deep structure of the West Iberia passive continental margin at $38^{\circ} \mathrm{N}$, Tectonophysics, 458(1-4), 9-50, doi:10.1016/j.tecto.2008.03.002, 2008.

Aslanian, D., Moulin, M., 2013. Palaeogeographic consequences of conservational models in the South Atlantic Ocean. Geol. Soc. Lond. Spec. Publ. 369, 75-90. doi:10.1144/SP369.5.

Aslanian, D., Moulin, M., Olivet, J.-L., Unternehr, P., Matias, L., Bache, F., Rabineau, M., Nouzé, H., Klingelheofer, F., Contrucci, I. and Labails, C.: Brazilian and African passive margins of the Central Segment of the South Atlantic Ocean: Kinematic constraints, Tectonophysics, 468(14), 98-112, doi:10.1016/j.tecto.2008.12.016, 2009.

Auffret, Y., Pelleau, P., Klingelhoefer, F., Geli, L., Crozon, J., Lin, J.Y., Sibuet, J.-C., 2004. MicrOBS: A new generation of ocean bottom seismometer. First Break 22. doi:10.3997/13652397.2004012.

Austin, J.A., Stoffa, P.L., Phillips, J.D., Oh, J., Sawyer, D.S., Purdy, G.M., Reiter, E., Makris, J., 1990. Crustal structure of the Southeast Georgia embayment-Carolina trough: Preliminary results of a composite seismic image of a continental suture and a volcanic passive margin. Geology 18, 1023-1027. doi:10.1130/0091-7613(1990)018<1023:CSOTSG>2.3.CO;2.

Ayarza, P., Carbonell, R., Teixell, A., Palomeras, I., Martí, D., Kchikach, A., Harnafi, M., Levander, A., Gallart, J., Arboleya, M. L., Alcalde, J., Fernández, M., Charroud, M. and Amrhar, M., 2014. Crustal thickness and velocity structure across the Moroccan Atlas from long offset wideangle reflection seismic data: The SIMA experiment, Geochem. Geophys. Geosyst., 15(5), 1698-1717, doi:10.1002/2013GC005164.

Barton, A.J., White, R.S., 1997. Crustal structure of Edoras Bank continental margin and mantle thermal anomalies beneath the North Atlantic. J. Geophys. Res. Solid Earth 102, 3109-3129. doi:10.1029/96JB03387.

Bauer, K., Neben, S., Schreckenberger, B., Emmermann, R., Hinz, K., Fechner, N., Gohl, K., Schulze, A., Trumbull, R.B., Weber, K., 2000. Deep structure of the Namibia continental margin as derived from integrated geophysical studies. J. Geophys. Res. Solid Earth 105, 25829-25853. doi:10.1029/2000JB900227.

Block, M., Reichert, C., Berglar, K., Schnabel, M., Klingelhoefer, F., Schnurle, P., 2012. The oceancontinent transition along the NW Moroccan margin-A new insight, in: EGU General Assembly Conference Abstracts. p. 7974.

Boillot, G., Beslier, M.O., Girardeau, J., 1995. Nature, Structure and Evolution of the Ocean-Continent Boundary: The Lesson of the West Galicia Margin (Spain), in: Banda, E., Torné, M., Talwani, M. (Eds.), Rifted Ocean-Continent Boundaries, NATO ASI Series. Springer Netherlands, pp. 219-229.

Boillot, G., Féraud, G., Recq, M., Girardeau, J., 1989. Undercrusting by serpentinite beneath rifted margins. Nature 341, 523-525. doi:10.1038/341523a0.

Bullard, E., Everett, J.E., Smith, A.G., 1965. The Fit of the Continents around the Atlantic. Philos. Trans. R. Soc. Lond. Ser. Math. Phys. Sci. 258, 41-51. doi:10.1098/rsta.1965.0020.

Chian, D., Louden, K.E., Reid, I., 1995. Crustal structure of the Labrador Sea conjugate margin and implications for the formation of nonvolcanic continental margins. J. Geophys. Res. Solid Earth 100, 24239-24253. doi:10.1029/95JB02162.

Choubert, G., Faure-Muret, A. and Sougy, J, 1968. Carte tectonique internationale de l'Afrique. UNESCO, 9 cartes.

Christensen, N.I., Mooney, W.D., 1995. Seismic velocity structure and composition of the continental crust: A global view. J. Geophys. Res. Solid Earth 100, 9761-9788. doi:10.1029/95JB00259.

Cohen, J.K., Stockwell Jr, J.W., 2003. CWP/SU: Seismic Unix Release 37: A free package for seismic research and processing. Cent. Wave Phenom. Colo. Sch. Mines. 
Contrucci, I., Klingelhoefer, F., Perrot, J., Bartolome, R., Gutscher, M.-A., Sahabi, M., Malod, J., Rehault, J.-P., 2004. The crustal structure of the NW Moroccan continental margin from wide-angle and reflection seismic data. Geophys. J. Int. 159, 117-128. doi:10.1111/j.1365246X.2004.02391.x.

Dean, S.M., Minshull, T.A., Whitmarsh, R.B., Louden, K.E., 2000. Deep structure of the oceancontinent transition in the southern Iberia Abyssal Plain from seismic refraction profiles: The IAM-9 transect at $40^{\circ} 20^{\prime} \mathrm{N}$. J. Geophys. Res. Solid Earth 105, 5859-5885. doi:10.1029/1999JB900301.

Dehler, S.A., 2011. Initial rifting and break-up between Nova Scotia and Morocco: An examination of new geophysical data and models. CM 2010 - Abstr. 8.

Drake, C.L., Ewing, M., Sutton, G.H., 1959. Continental margins and geosynclines: The east coast of North America north of Cape Hatteras. Phys. Chem. Earth 3, 110-198. doi:10.1016/00791946(59)90005-9.

Fowler, S.R., White, R.S., Spence, G.D., Westbrook, G.K., 1989. The Hatton Bank continental marginII. Deep structure from two-ship expanding spread seismic profiles. Geophys. J. Int. 96, 295309. doi:10.1111/j.1365-246X.1989.tb04452.x.

Fullea, J., Fernàndez, M., Afonso, J.C., Vergés, J., Zeyen, H., 2010. The structure and evolution of the lithosphere-asthenosphere boundary beneath the Atlantic-Mediterranean Transition Region. Lithos, The lithosphere/asthenosphere boundary: Nature, formation and evolution Session EIL-03 of the International Geological Congress 120, 74-95. doi:10.1016/j.lithos.2010.03.003.

Funck, T., Hopper, J.R., Larsen, H.C., Louden, K.E., Tucholke, B.E., Holbrook, W.S., 2003. Crustal structure of the ocean-continent transition at Flemish Cap: Seismic refraction results. J. Geophys. Res. Solid Earth 108, 2531. doi:10.1029/2003JB002434.

Funck, T., Jackson, H.R., Louden, K.E., Dehler, S.A., Wu, Y., 2004. Crustal structure of the northern Nova Scotia rifted continental margin (eastern Canada). J. Geophys. Res. Solid Earth 109n, B09102, doi:10.1029/2004JB003008.

Gradstein, F.M., Ogg, J.G., Smith, A.G., Bleeker, W., Lourens, L.J., 2004. A new geologic time scale, with special reference to Precambrian and Neogene. Episodes 27, 83-100.

Hames, W.E., Renne, P.R., Ruppel, C., 2000. New evidence for geologically instantaneous emplacement of earliest Jurassic Central Atlantic magmatic province basalts on the North American margin. Geology 28, 859-862. doi:10.1130/00917613(2000)28<859:NEFGIE>2.0.CO;2.

Hames, W., McHone, J., Renne, P., Ruppel, C., 2003. The Central Atlantic Magmatic Province: Insights from Fragments of Pangea. Presented at the Geophysical Monograph Series; American Geophysical Union, pp. 1-267.

Hinz, K., 1981. A hypothesis on terrestrial catastrophes: Wedges of very thick oceanward dipping layers beneath passive continental margins; their origin and paleoenvironmental significance. Schweizerbart.

Hinz, K., Dostmann, H., Fritsch, J., 1982. The Continental Margin of Morocco: Seismic Sequences, Structural Elements and Geological Development, in: Rad, D.U. von, Hinz, P.D.K., Sarnthein, P.D.M., Seibold, P.D.E. (Eds.), Geology of the Northwest African Continental Margin. Springer Berlin Heidelberg, pp. 34-60.

Holbrook, W.S., Kelemen, P.B., 1993. Large igneous province on the US Atlantic margin and implications for magmatism during continental breakup. Nature 364, 433-436. doi:10.1038/364433a0.

Holbrook, W.S., Reiter, E.C., Purdy, G.M., Sawyer, D., Stoffa, P.L., Austin, J.A., Oh, J., Makris, J., 1994. Deep structure of the U.S. Atlantic continental margin, offshore South Carolina, from coincident ocean bottom and multichannel seismic data. J. Geophys. Res. Solid Earth 99, 9155-9178. doi:10.1029/93JB01821. 
Holik, J.S., Rabinowitz, P.D., Austin, J.A., 1991. Effects of Canary hotspot volcanism on structure of oceanic crust off Morocco. J. Geophys. Res. Solid Earth 96, 12039-12067. doi:10.1029/91JB00709.

Jaffal, M., Klingelhoefer, F., Matias, L., Teixeira, F., Amrhar, M., 2009. Crustal structure of the NW Moroccan margin from deep seismic data (SISMAR Cruise). Comptes Rendus Geosci. 341, 495-503. doi:10.1016/j.crte.2009.04.003.

Jansa, L.F., 1981. Mesozoic carbonate platforms and banks of the eastern North American margin. Mar. Geol. 44, 97-117. doi:10.1016/0025-3227(81)90114-6.

Keller, F.., Menschke, J.., Alldredge, L.., 1954. Aeromagnetic surveys in the Aleutian, Marshall, and Bermuda Islands. Presented at the American Geophysical Union, pp. 558-572. doi:10.1029/TR035i004p00558.

Klingelhoefer, F., Labails, C., Cosquer, E., Rouzo, S., Géli, L., Aslanian, D., Olivet, J.-L., Sahabi, M., Nouzé, H., Unternehr, P., 2009. Crustal structure of the SW-Moroccan margin from wideangle and reflection seismic data (the DAKHLA experiment) Part A: Wide-angle seismic models. Tectonophysics 468, 63-82. doi:10.1016/j.tecto.2008.07.022.

Klitgord, K., Schouten, H., 1986. Plate kinematics of the central Atlantic. Geol. N. Am. 1000, 351-378.

Knight, K.B., Nomade, S., Renne, P.R., Marzoli, A., Bertrand, H., Youbi, N., 2004. The Central Atlantic Magmatic Province at the Triassic-Jurassic boundary: paleomagnetic and 40Ar/39Ar evidence from Morocco for brief, episodic volcanism. Earth Planet. Sci. Lett. 228, 143-160. doi:10.1016/j.epsl.2004.09.022

Korenaga, J., Kelemen, P.B., Holbrook, W.S., 2002. Methods for resolving the origin of large igneous provinces from crustal seismology. J. Geophys. Res. Solid Earth 107, 2178. doi:10.1029/2001JB001030

Labails, C., Olivet, J.-L., 2009. Crustal structure of the SW Moroccan margin from wide-angle and reflection seismic data (the Dakhla experiment). Part B - The tectonic heritage. Tectonophysics 468, 83-97. doi:10.1016/j.tecto.2008.08.028.

Labails, C., Olivet, J.-L., Aslanian, D., Roest, W.R., 2010. An alternative early opening scenario for the Central Atlantic Ocean. Earth Planet. Sci. Lett. 297, 355-368. doi:10.1016/j.epsl.2010.06.024.

Leprêtre, A., Klingelhoefer, F., Graindorge, D., Schnurle, P., Beslier, M.O., Yelles, K., Déverchère, J., Bracene, R., 2013. Multiphased tectonic evolution of the Central Algerian margin from combined wide-angle and reflection seismic data off Tipaza, Algeria. J. Geophys. Res. Solid Earth 118, 3899-3916. doi:10.1002/jgrb.50318.

Le Roy, P., 1997. Les bassins Ouest-marocains; leur formation et leur évolution dans le cadre de l'ouverture et du développement de l'Atlantique central (Marge africaine). Thèse de doctorat de l'Université de Bretagne Occidentale, Brest, 327p.

Le Roy, P., Piqué, A., 2001. Triassic-Liassic Western Moroccan synrift basins in relation to the Central Atlantic opening. Mar. Geol. 172, 359-381. doi:10.1016/S0025-3227(00)00130-4.

Le Roy, P., Pique, A., Gall, B.L., Brahim, L.A., Morabet, A.M., Demnati, A., 1997. Les bassins cotiers triasico-liasiques du Maroc occidental et la diachronie du rifting intra-continental de I'Atlantique central. Bull. Soc. Geol. Fr. 168, 637-648.

Lister, G.S., Davis, G.A., 1989. The origin of metamorphic core complexes and detachment faults formed during Tertiary continental extension in the northern Colorado River region, U.S.A. J. Struct. Geol. 11, 65-94. doi:10.1016/0191-8141(89)90036-9.

Louden, K., Lau, H., Wu Y., and Nedimovic, M., (2010) Chapter 2 : Plate tectonics, in : PLAY FAIRWAY Analysis Offshore Nova Scotia Canada Atlas.

Ludwig, W.J., Nafe, J.E., Drake, C.L., 1970. Seismic refraction. The Sea 4, 53-84.

Luheshi, M., Roberts, D.G., Nunn, K., Makris, J., Colletta, B., Wilson, H., Monnier, F., Rabary, G., Dubille, M., 2012. The impact of conjugate margins analysis on PLAY FAIRWAY evaluation-an analysis of the hydrocarbon potential of Nova Scotia. First Break 30, 61-72.

Maillard, A., Malod, J., Thiébot, E., Klingelhoefer, F., Réhault, J.-P., 2006. Imaging a lithospheric detachment at the continent-ocean crustal transition off Morocco. Earth Planet. Sci. Lett. 241, 686-698. doi:10.1016/j.epsl.2005.11.013. 
Makris, J., Demnati, A., Klussmann, J., 1985. Deep seismic soundings in Morocco and a crust and upper mantle model deduced from seismic and gravity data. Ann. Geophys. 3, 369-380.

Marzoli, A., Bertrand, H., Knight, K.B., Cirilli, S., Buratti, N., Vérati, C., Nomade, S., Renne, P.R., Youbi, N., Martini, R., Allenbach, K., Neuwerth, R., Rapaille, C., Zaninetti, L., Bellieni, G., 2004. Synchrony of the Central Atlantic magmatic province and the Triassic-Jurassic boundary climatic and biotic crisis. Geology 32, 973-976. doi:10.1130/G20652.1.

McHone, J.G., 2000. Non-plume magmatism and rifting during the opening of the central Atlantic Ocean. Tectonophysics 316, 287-296. doi:10.1016/S0040-1951(99)00260-7.

McKenzie, D., 1978. Some remarks on the development of sedimentary basins. Earth Planet. Sci. Lett. 40, 25-32. doi:10.1016/0012-821X(78)90071-7.

Michard, A., Saddiqi, O., Chalouan, A., Frizon de lamotte, D., 2008. Continental Evolution: The Geology of Morocco: Structure, Stratigraphy, and Tectonics of the Africa-AtlanticMediterranean Triple Junction. Springer Science \& Business Media.

Morgan, J.V., Barton, P.J., White, R.S., 1989. The Hatton Bank continental margin -III. Structure from wide-angle OBS and multichannel seismic refraction profiles. Geophys. J. Int. 98, 367-384. doi:10.1111/j.1365-246X.1989.tb03358.x.

ODP Leg 173 Shipboard Scientific Party, 1998. Drilling reveals transition from continental breakup to early magmatic crust. Eos Trans. Am. Geophys. Union 79, 173-181. doi:10.1029/98EO00127.

Olivet, J.L., Bonnin, J., Beuzart, P., Auzende, J.-M., 1984. Cinématique de l'Atlantique Nord et Central. Publ. CNEXO Sér. Rapp. Sci. Tech. 54, 1-108.

Olsen, P.E., 1999. Enhanced: Giant Lava Flows, Mass Extinctions, and Mantle Plumes. Science 284, 604-605.

Palomeras, I., Thurner, S., Levander, A., Liu, K., Villasenor, A., Carbonell, R., Harnafi, M., 2014. Finitefrequency Rayleigh wave tomography of the western Mediterranean: Mapping its lithospheric structure. Geochem. Geophys. Geosystems 15, 140-160. doi:10.1002/2013GC004861.

Pautot, G., Le Pichon, X., 1970. Continuous Deep Sea Salt Layer along North Atlantic Margins related to Early Phase of Rifting. Nature 227, 351-354.

Roeser, H.A., 1982. Magnetic Anomalies in the Magnetic Quiet Zone off Morocco, in: Rad, D.U. von, Hinz, P.D.K., Sarnthein, P.D.M., Seibold, P.D.E. (Eds.), Geology of the Northwest African Continental Margin. Springer Berlin Heidelberg, pp. 61-68.

Roeser, H.A., Steiner, C., Schreckenberger, B., Block, M., 2002. Structural development of the Jurassic Magnetic Quiet Zone off Morocco and identification of Middle Jurassic magnetic lineations. J. Geophys. Res. Solid Earth 107, 2207. doi:10.1029/2000JB000094.

Sahabi, M., 2004. Évolution cinématique triasico-jurassique de l'Atlantique central : implications sur l'évolution géodynmaique des marges homologues nord-ouest africaine et est américaine. Thèse de doctorat d'État Es-Science, Université Chouaïb Doukkali, El Jadida, 615p.

Sahabi, M., Aslanian, D., Olivet, J.-L., 2004. Un nouveau point de départ pour l'histoire de l'Atlantique central. Comptes Rendus Geosci. 336, 1041-1052. doi:10.1016/j.crte.2004.03.017.

Sengör, A.M.C., Burke, K., 1978. Relative timing of rifting and volcanism on Earth and its tectonic implications. Geophys. Res. Lett. 5, 419-421. doi:10.1029/GL005i006p00419.

Sheridan, R., Musser, D.., Glover, L., Talwani, M., Ewing, J.., Holbrook, W.S., Purdy, G.., Hawman, R., Smithson, S., 1993. Deep seismic reflection data of EDGE U.S. mid-Atlantic continentalmargin experiment: Implications for Appalachian sutures and Mesozoic rifting and magmatic underplating. Geology 21, 563-567. doi:10.1130/0091-7613(1993)021<0563:DSRDOE> 2.3.CO;2.

Sibuet, J.-C., Rouzo, S., Srivastava, S., Dehler, S., Deptuck, M., Karim, A., 2012. Plate tectonic reconstructions and paleogeographic maps of the central and North Atlantic oceans. Can. J. Earth Sci. 49, 1395-1415. doi:10.1139/e2012-071.

Smith, W.H.F., Sandwell, D., 1997. Global seafloor topography from satellite altimetry and ship depth soundings. Science 277, 1956-1962. 
Stockwell Jr., J.W., 1999. The CWP/SU: Seismic Un*x package,. Comput. Geosci. 25, 415-419. doi:10.1016/S0098-3004(98)00145-9.

Talwani, M., Ewing, J., Sheridan, R.E., Holbrook, W.S., Glover, L., 1995. The EDGE Experiment and the U.S. East Coast Magnetic Anomaly, in: Banda, E., Torné, M., Talwani, M. (Eds.), Rifted OceanContinent Boundaries. Springer Netherlands, Dordrecht, pp. 155-181.

Tari, G., Molnar, J., 2005. Correlation of syn-rift structures between Morocco and Nova Scotia, Canada, in: Transactions GCSSEPM Foundation, 25th Ann. Res. Conf. SEPM, pp. 132-150.

Tari, G., Molnar, J., Ashton, P., 2003. Examples of salt tectonics from West Africa: a comparative approach. Geol. Soc. Lond. Spec. Publ. 207, 85-104. doi:10.1144/GSL.SP.2003.207.01.05.

Van Avendonk, H.J.A., Holbrook, W.S., Nunes, G.T., Shillington, D.J., Tucholke, B.E., Louden, K.E., Larsen, H.C., Hopper, J.R., 2006. Seismic velocity structure of the rifted margin of the eastern Grand Banks of Newfoundland, Canada. J. Geophys. Res. Solid Earth 111, B11404. doi:10.1029/2005JB004156.

Van Avendonk, H.J.A., Lavier, L.L., Shillington, D.J., Manatschal, G., 2009. Extension of continental crust at the margin of the eastern Grand Banks, Newfoundland. Tectonophysics, Role of magmatism in continental lithosphere extension continental lithosphere extension 468, 131148. doi:10.1016/j.tecto.2008.05.030.

Verhoef, J., Roest, W.R., Macnab, R., Arkani-Hamed, J., Members of the Project Team, 1996. Magnetic anomalies of the Arctic and North Atlantic oceans and adjacent land areas. Geol Surv Can. Open File 3125.

Vogt, U., Makris, J., O’Reilly, B.M., Hauser, F., Readman, P.W., Jacob, A.W.B., Shannon, P.M., 1998. The Hatton Basin and continental margin: Crustal structure from wide-angle seismic and gravity data. J. Geophys. Res. Solid Earth 103, 12545-12566. doi:10.1029/98JB00604.

Weigel, W., Wissmann, G., Goldflam, P., 1982. Deep Seismic Structure (Mauritania and Central Morocco), in: Rad, D.U. von, Hinz, P.D.K., Sarnthein, P.D.M., Seibold, P.D.E. (Eds.), Geology of the Northwest African Continental Margin. Springer Berlin Heidelberg, pp. 132-159.

Wernicke, B., 1985. Uniform-sense normal simple shear of the continental lithosphere. Can. J. Earth Sci. 22, 108-125. doi:10.1139/e85-009.

Wessel, P., Smith, W.H.F., 1995. New version of the generic mapping tools. Eos Trans. Am. Geophys. Union 76, 329-329. doi:10.1029/95EO00198.

White, R.S., McKenzie, D., O'Nions, R.K., 1992. Oceanic crustal thickness from seismic measurements and rare earth element inversions. J. Geophys. Res. Solid Earth 1978-2012 97, 19683-19715. doi:10.1029/92JB01749.

White, R.S., Smith, L.K., Roberts, A.W., Christie, P. a. F., Kusznir, N.J., Roberts, A.M., Healy, D., Spitzer, R., Chappell, A., Eccles, J.D., Fletcher, R., Hurst, N., Lunnon, Z., Parkin, C.J., Tymms, V.J., 2008. Lower-crustal intrusion on the North Atlantic continental margin. Nature 452, 460-464. doi:10.1038/nature06687.

Whitmarsh, R.B., Manatschal, G., Minshull, T.A., 2001. Evolution of magma-poor continental margins from rifting to seafloor spreading. Nature 413, 150-154. doi:10.1038/35093085.

Wu, Y., Louden, K.E., Funck, T., Jackson, H.R., Dehler, S.A., 2006. Crustal structure of the central Nova Scotia margin off Eastern Canada. Geophys. J. Int. 166, 878-906. doi:10.1111/j.1365246X.2006.02991.X.

Zelt, C.A., Smith, R.B., 1992. Seismic traveltime inversion for 2-D crustal velocity structure. Geophys. J. Int. 108, 16-34. doi:10.1111/j.1365-246X.1992.tb00836.x. 


\begin{tabular}{|c|c|c|c|c|c|c|c|c|c|c|c|}
\hline $\begin{array}{c}\text { Phase/MI- } \\
01\end{array}$ & $\begin{array}{l}\text { Number } \\
\text { Of data }\end{array}$ & RMS(s) & $\mathrm{Chi}^{2}$ & $\begin{array}{c}\text { Phase/MI- } \\
02\end{array}$ & $\begin{array}{l}\text { Number } \\
\text { Of data }\end{array}$ & RMS(s) & $\mathrm{Chi}^{2}$ & $\begin{array}{c}\text { Phase/MI- } \\
03\end{array}$ & $\begin{array}{l}\text { Number } \\
\text { Of data }\end{array}$ & RMS(s) & $\mathrm{Chi}^{2}$ \\
\hline Direct & 1857 & 0.020 & 0.466 & Direct & 795 & 0.025 & 0.673 & Direct & 512 & 0.027 & 0.807 \\
\hline PS2 & 608 & 0.123 & 4.230 & PS2 & 452 & 0.083 & 1.899 & PS2 & 402 & 0.093 & 2.413 \\
\hline PS3 & 997 & 0.051 & 0.724 & PS3 & 556 & 0.116 & 3.723 & PS3 & 315 & 0.069 & 1.318 \\
\hline PS1P & 953 & 0.098 & 2.666 & PS1P & 635 & 0.070 & 1.374 & PS1P & 247 & 0.083 & 1.944 \\
\hline$P S 2 P$ & 797 & 0.075 & 1.572 & PS2P & 243 & 0.085 & 2.002 & $P S 2 P$ & 306 & 0.072 & 1.450 \\
\hline PS3P & 192 & 0.098 & 2.685 & & & & & & & & \\
\hline$P B P$ & 736 & 0.167 & 3.461 & $P B P$ & 353 & 0.119 & 1.766 & $P B P$ & 220 & 0.072 & 0.638 \\
\hline Pc1 & 2456 & 0.181 & 2.963 & Pc1 & 981 & 0.118 & 1.729 & Pc1 & 2848 & 0.139 & 2.400 \\
\hline$P C 2$ & 6876 & 0.133 & 2.022 & Pc2 & 3318 & 0.078 & 0.751 & Pc2 & 998 & 0.116 & 1.665 \\
\hline$P \mathrm{~m} P$ & 2249 & 0.153 & 1.522 & $P \mathrm{~m} P$ & 715 & 0.161 & 1.804 & $P \mathrm{mP}$ & 1491 & 0.133 & 1.229 \\
\hline$P \mathrm{n}$ & 4152 & 0.161 & 1.689 & $P \mathrm{n}$ & 2328 & 0.104 & 0.748 & $P \mathrm{n}$ & 413 & 0.161 & 1.811 \\
\hline $\begin{array}{c}\text { Phase/MI- } \\
04\end{array}$ & $\begin{array}{l}\text { Number } \\
\text { Of data }\end{array}$ & RMS(s) & $\mathrm{Chi}^{2}$ & $\begin{array}{c}\text { Phase/MI- } \\
05\end{array}$ & $\begin{array}{l}\text { Number } \\
\text { Of data }\end{array}$ & RMS(s) & $\mathrm{Chi}^{2}$ & $\begin{array}{c}\text { Phase/MI- } \\
06\end{array}$ & $\begin{array}{l}\text { Number } \\
\text { Of data }\end{array}$ & RMS(s) & $\mathrm{Chi}^{2}$ \\
\hline Direct & 676 & 0.044 & 2.137 & Direct & 897 & 0.045 & 2.226 & Direct & 1082 & 0.024 & 0.634 \\
\hline PS1 & 371 & 0.075 & 1.567 & PS1 & 437 & 0.073 & 1.491 & PS1 & 504 & 0.143 & 5.664 \\
\hline PS2 & 224 & 0.138 & 5.301 & PS2 & 293 & 0.110 & 3.382 & PS2 & 271 & 0.106 & 3.142 \\
\hline PS3 & 260 & 0.128 & 4.537 & PS3 & 1044 & 0.158 & 6.961 & PS3 & 1139 & 0.051 & 0.727 \\
\hline PS1P & 330 & 0.087 & 2.129 & PS1P & 534 & 0.073 & 1.480 & PS1P & 819 & 0.040 & 0.445 \\
\hline$P S 2 P$ & 300 & 0.130 & 4.741 & $P S 2 P$ & 342 & 0.085 & 0.904 & $P S 2 P$ & 628 & 0.116 & 3.738 \\
\hline$P B P$ & 0 & 0 & 0 & $P B P$ & 277 & 0.114 & 3.619 & $P B P$ & 659 & 0.128 & 2.030 \\
\hline Pc1 & 1075 & 0.140 & 2.411 & Pc1 & 1149 & 0.176 & 2.153 & Pc1 & 1175 & 0.132 & 2.165 \\
\hline$P \mathrm{c} 2$ & 1143 & 0.128 & 2.040 & Pc2 & 826 & 0.110 & 3.361 & $P \mathrm{c} 2$ & 2851 & 0.109 & 1.463 \\
\hline$P \mathrm{~m} P$ & 978 & 0.160 & 1.773 & $P \mathrm{~m} P$ & 908 & 0.136 & 2.296 & $P \mathrm{mP}$ & 793 & 0.138 & 1.332 \\
\hline$P \mathrm{n}$ & 46 & 0.100 & 0.715 & $P \mathrm{n}$ & 813 & 0.120 & 1.791 & $P \mathrm{n}$ & 632 & 0.062 & 0.266 \\
\hline $\begin{array}{c}\text { Phase/MI- } \\
07\end{array}$ & $\begin{array}{l}\text { Number } \\
\text { Of data }\end{array}$ & RMS(s) & $\mathrm{Chi}^{2}$ & \multicolumn{8}{|c|}{ Glossary of seismic phases } \\
\hline Direct & 1013 & 0.030 & 0.892 & Direct & \multicolumn{7}{|c|}{ Direct wave through the water } \\
\hline PS1 & 249 & 0.125 & 3.546 & PSn & \multicolumn{7}{|c|}{ P-wave refracted phase through the nth post-rift sedimentary layer from the top } \\
\hline PS2 & 372 & 0.104 & 2.995 & $P_{s n P}$ & \multicolumn{7}{|c|}{$\begin{array}{l}\text { P-wave reflected phase from the bottom of the } n \text {th post-rift sedimentary layer } \\
\text { from the top }\end{array}$} \\
\hline PS3 & 762 & 0.122 & 3.334 & $P \mathrm{~B} P$ & \multicolumn{7}{|c|}{ P-wave reflected phase from the basement top } \\
\hline PS1P & 810 & 0.051 & 0.719 & $P \mathrm{c} 1 / P_{\mathrm{c} 2}$ & \multicolumn{7}{|c|}{ P-wave refracted phase through the upper/lower continental crust } \\
\hline PS2P & 282 & 0.086 & 2.085 & $P \mathrm{~m} P$ & \multicolumn{7}{|c|}{ P-wave Moho reflection or reflection at the crust-mantle boundary } \\
\hline PBP & 442 & 0.054 & 0.202 & $P_{\mathrm{n}}$ & \multicolumn{7}{|c|}{ P-wave refracted phase through the upper mantle } \\
\hline Pc1 & 216 & 0.081 & 0.823 & & & & & & & & \\
\hline Pc2 & 1745 & 0.102 & 1.284 & & & & & & & & \\
\hline$P \mathrm{mP}$ & 503 & 0.087 & 0.929 & & & & & & & & \\
\hline$P \mathrm{n}$ & 2730 & 0.084 & 0.494 & & & & & & & & \\
\hline All & 9124 & 0.087 & 1.197 & & & & & & & & \\
\hline
\end{tabular}

Tab.1: Residual traveltimes and chi-squared errors for all the phases for the MIRROR profiles, using forward modeling. 

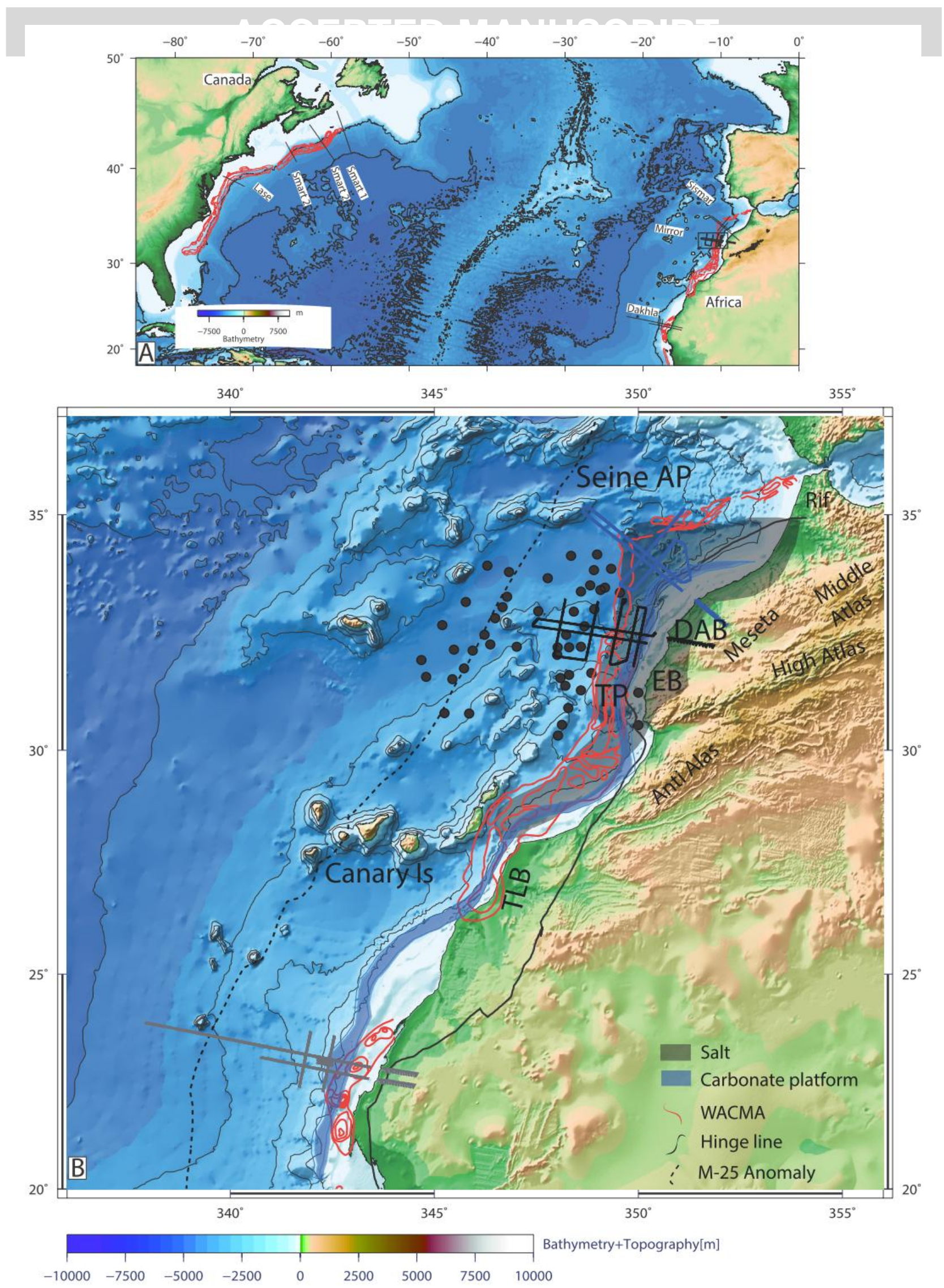

Fig.1: (A) Distribution of different wide-angle profile along the central Atlantic passive margin of NW Africa and North-America margins. (B) Bathymetry and topography of the Moroccan margin from satellite altimetry (Smith and Sandwell, 1997).The West African Coast Magnetic Anomaly (WACMA) is taken from Verhoef et al. (1996) and Roeser et al. (2002). The position of the salt is taken from Tari et al. (2003), Tari and Molnar (2005) and Sahabi et al. (2004) and that of the Hinge line from Sahabi et al. (2004) and Tari and Molnar (2005). The Jurassic carbonate platform is taken from Klitgord and Schouten (1986). Sedimentary basins are marked by abbreviations: DAB, Doukkala-Abda Basin; EAB, Essaouira-Agadir Basin; TLB, Tarfaya-Laâyoun Basin. The solid black lines mark the combined wide-angle and reflection-seismic profiles of the MIRROR cruise, the blue lines those of the SISMAR cruise, and gray lines those of the DAKHLA cruise. Black circles mark the position of the sonobuoy deployments from Holik (1991). 


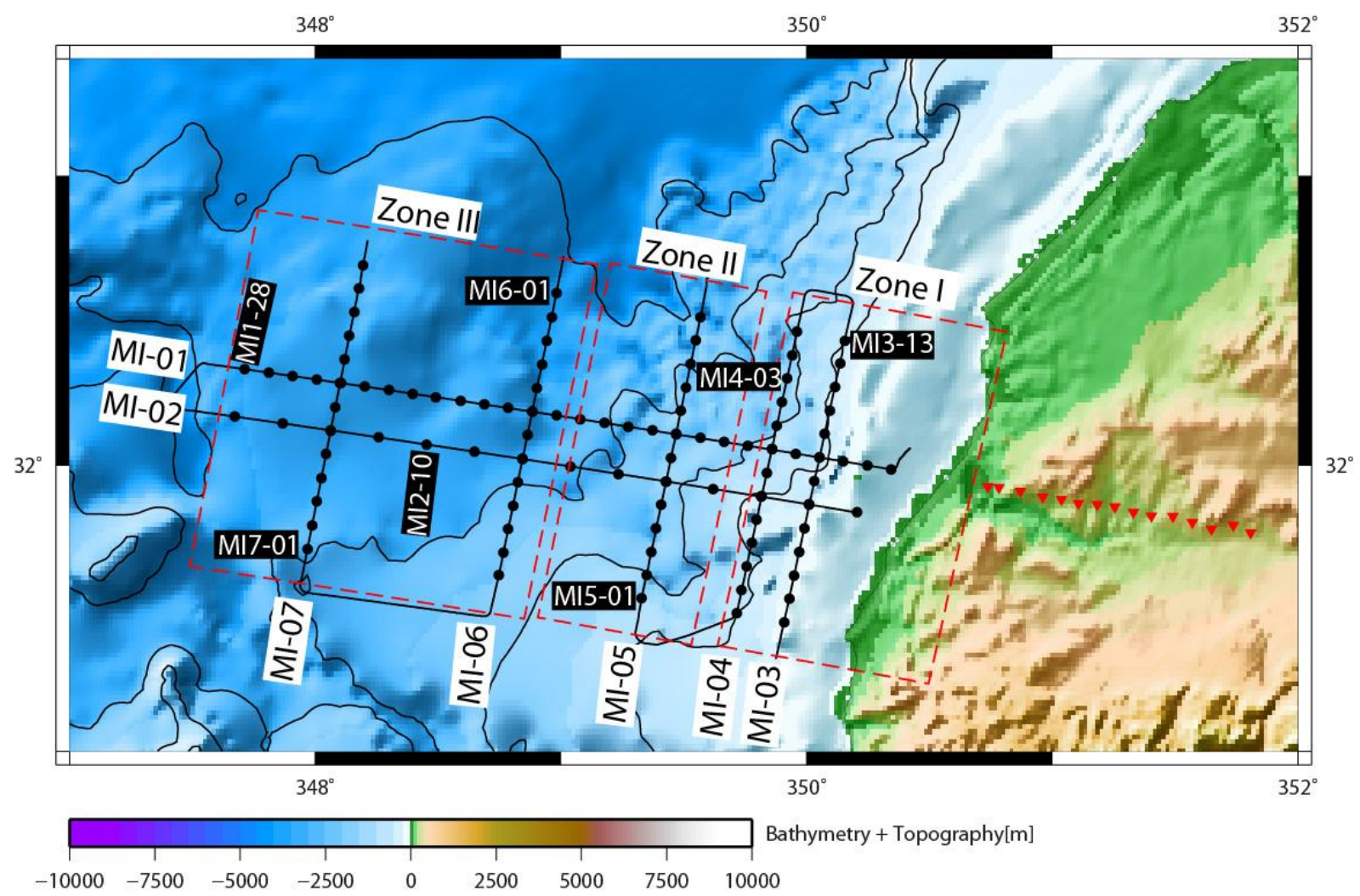

Fig.2: Location of the study area off the North-Western Moroccan continental margin. Bathymetric and topographic data are from satellite altimetry (Smith and Sandwell, 1997). Ocean bottom seismometer (OBS) positions are marked by black circles and the land stations by red triangles. The multi-channel seismic profiles are marked by black lines. 

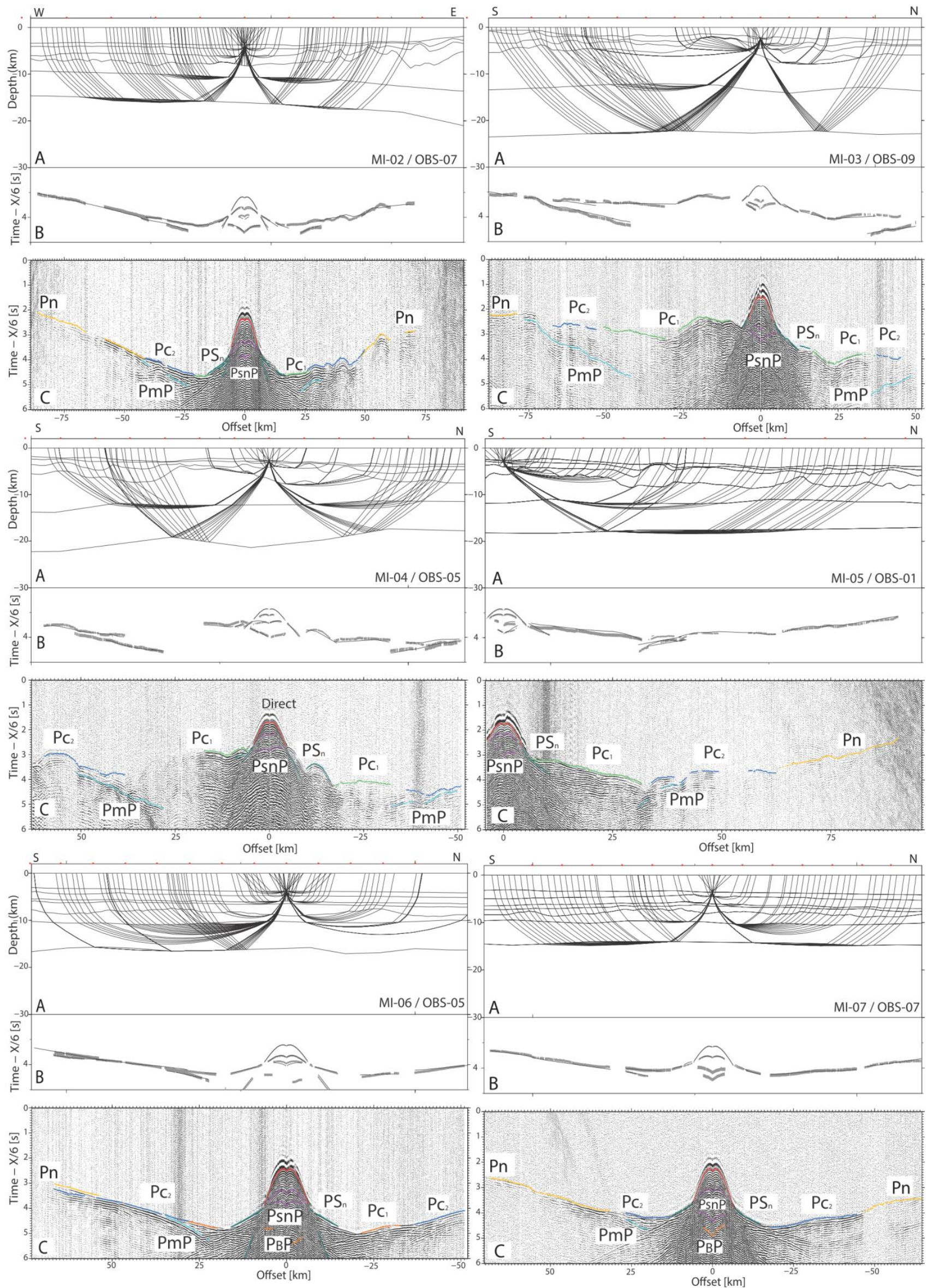

Fig.3: Modeled ray paths and seismic data for different stations (See Figure 2 for instrument positions). For each panel (A) Ray coverage of the sedimentary, crustal layers, Moho and upper mantle layers, with every tenth ray from two-point ray-tracing plotted.(B) Observed travel-time picks and calculated travel times (line) for all layers. (C) Examples of the wide-angle seismic data. Processing included a bandpass filter (5-4 Hz, 24-36 $\mathrm{Hz}$ ). The data are gain-adjusted according to offset and reduced to a velocity of $6 \mathrm{~km} / \mathrm{s}$. 

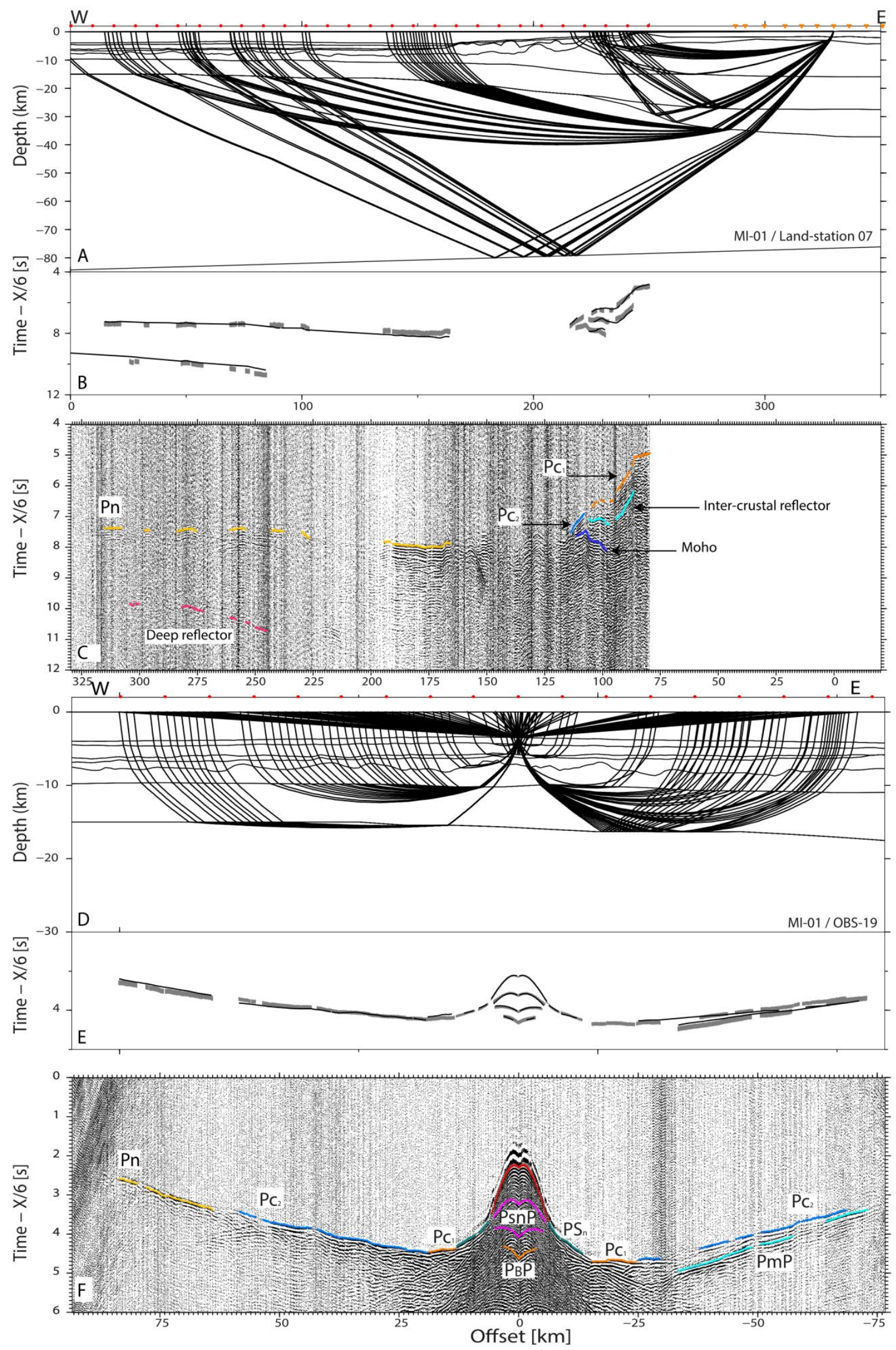

Fig.4: Upper panel (A) Ray coverage of the crustal layers, Moho and upper mantle layers for MI-01 with every tenth ray from two-point ray-tracing plotted.(B) Observed travel-time picks and calculated travel times (black line) for the crustal layers, Moho and upper mantle. (C) Data from landstation 07 with the same gain, filter and scaling applied as in Fig. 3. Lower panel (D) Ray coverage of the sedimentary, crustal layers, Moho and upper mantle layers, with every tenth ray from two-point ray-tracing plotted.(E) Observed travel-time picks and calculated travel times (line) for all layers. (F) Data from OBS 19 for MI-01 with the same gain, filter and scaling applied as in Fig. 3. 


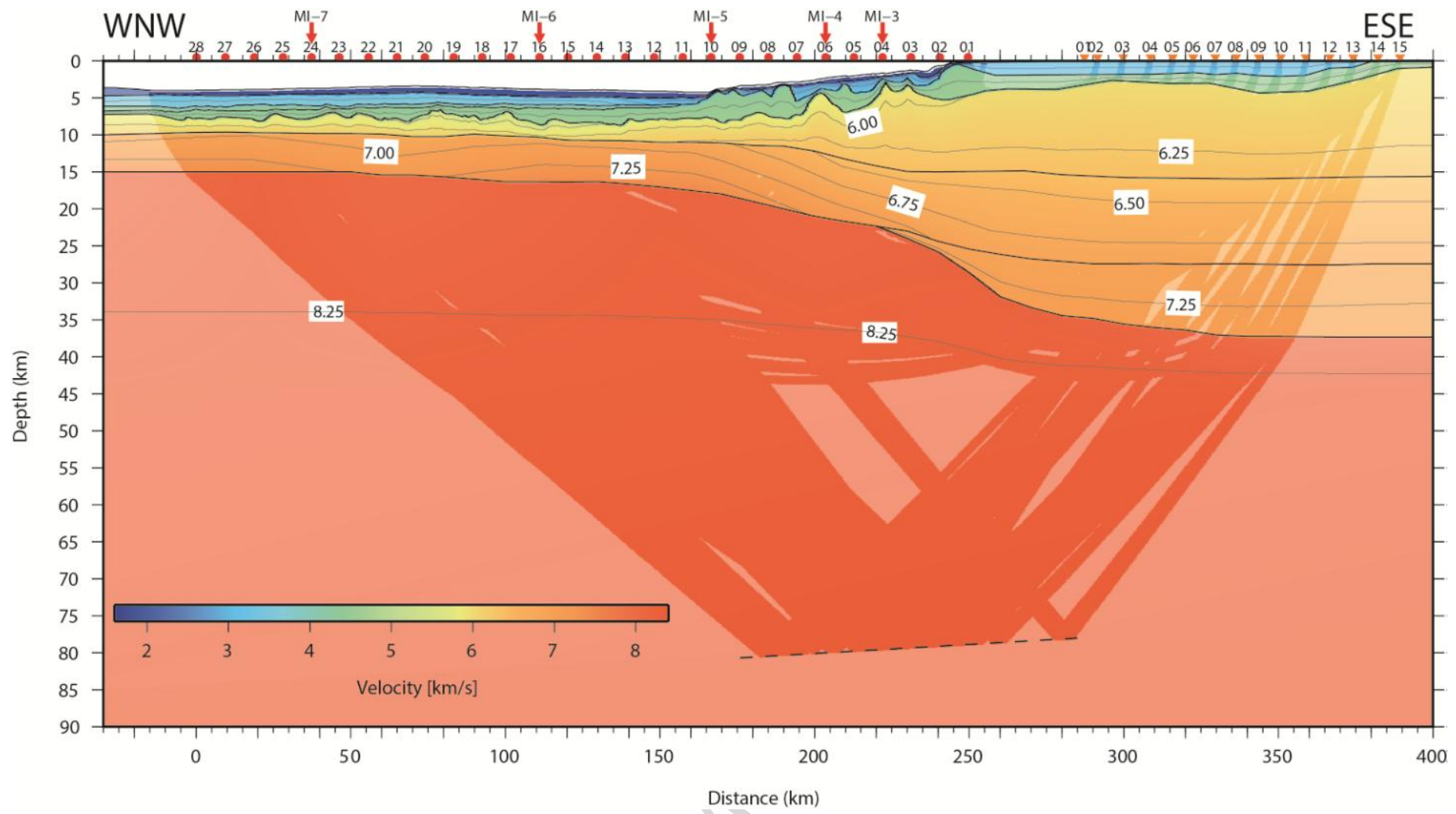

Fig.5: Final velocity model of profile MI-01. Boundaries of the velocity models are indicated and isovelocity contours every $0.25 \mathrm{~km} / \mathrm{s}$. Regions unconstrained by the ray-tracing are shaded. Positions of OBS (circles) and land-stations (orange inverted triangles) indicated. 


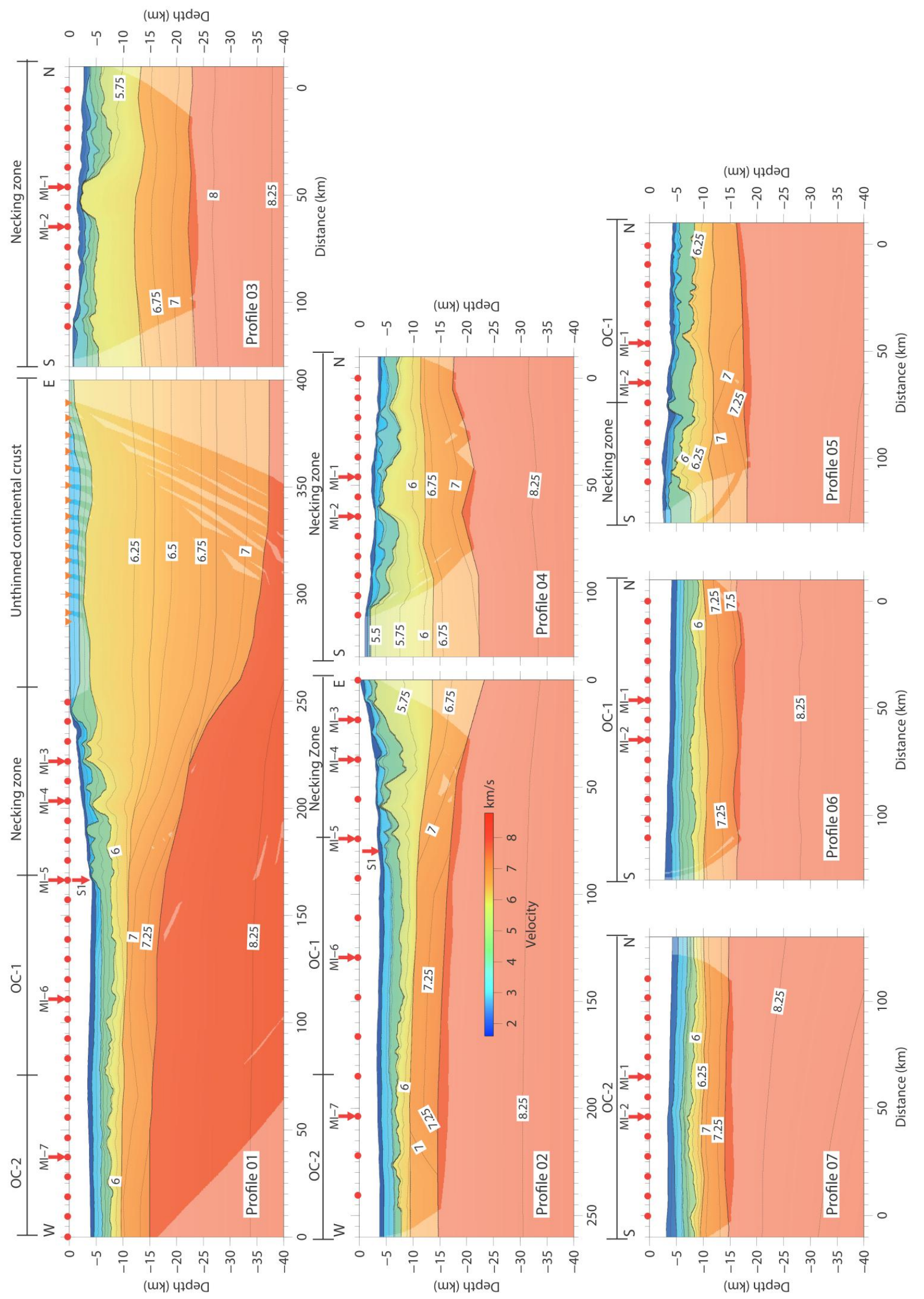

Fig.6: Final velocity model of MIRROR Profiles. Velocities are contoured at a $0.25 \mathrm{~km} / \mathrm{s}$ interval and black lines mark layer boundaries from the modeling. Shaded areas are unconstrained by seismic rays. OBS locations are indicated by red circles and landstation locations by orange inverted triangles. 


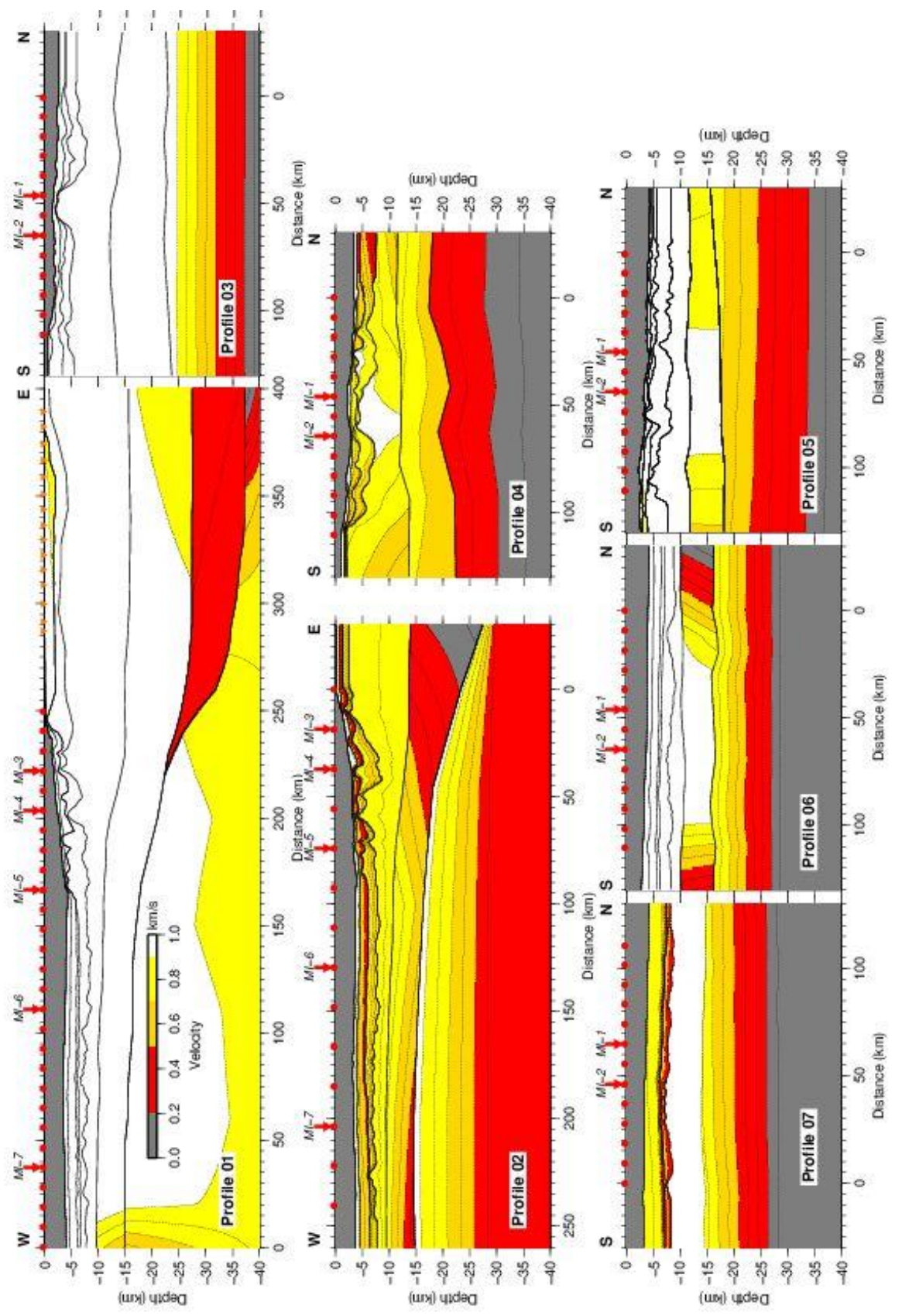

Fig.7: Resolution parameter for all velocity nodes of the final velocity models on all profiles. White and yellow areas can be considered well resolved. OBS positions are indicated by red circles and landstations by orange inverted triangles. 


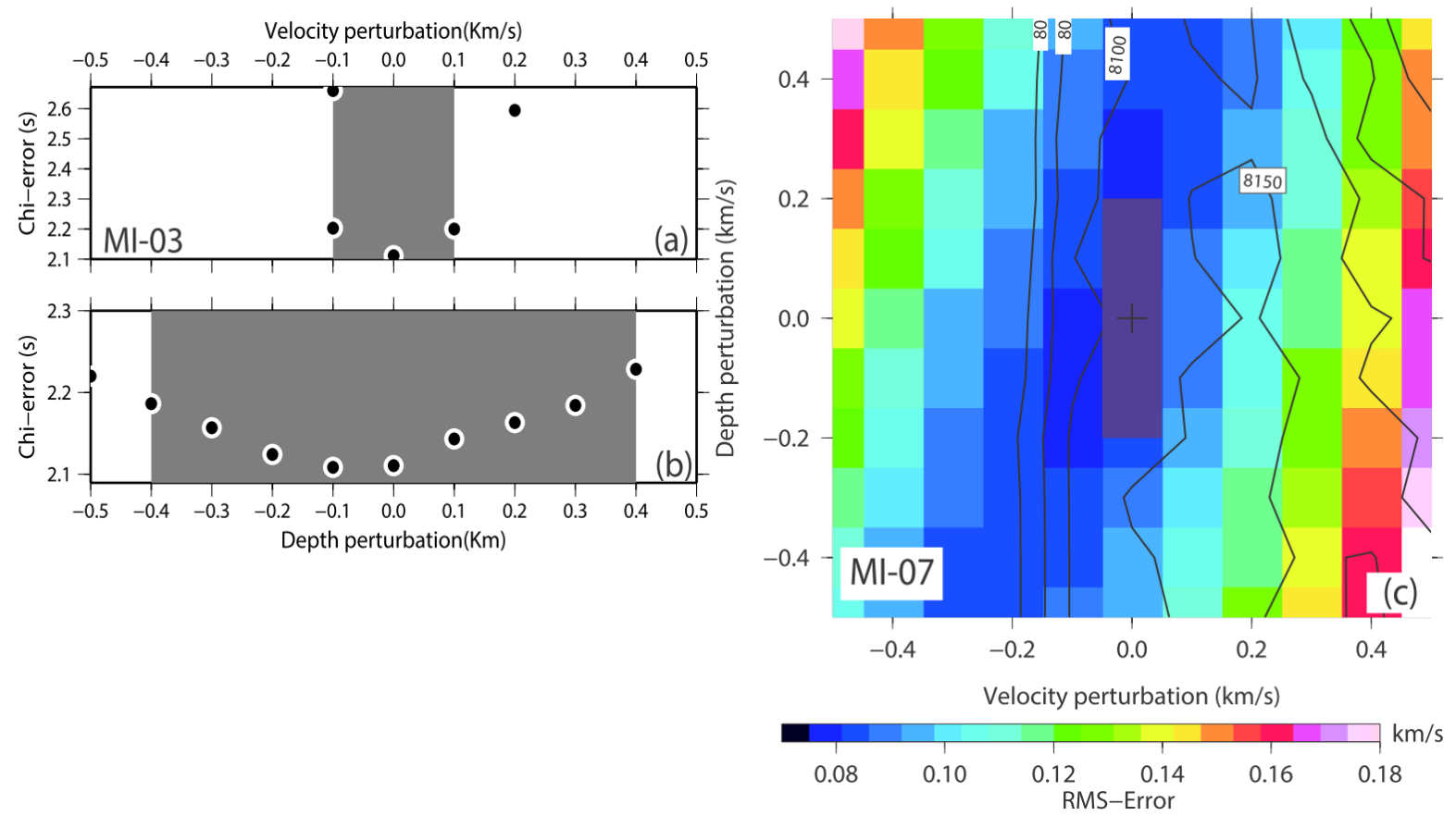

Fig.8: Error analysis by model perturbation. The uncertainties of the most important boundaries calculated from the $95 \%$ confidence limit of the $f$-test are given in the grey boxes. (a) Results from variation of the lower crustal velocities only. (b) Results from variation of the Moho depth. (c) Results from simultaneous variation of the depth of the Moho and velocities in the lower crustal layer. Contours indicate the number of picks explained by the forward model. 
Fig.9: Ray density on all profiles. Red circles mark OBS positions, orange inverted triangle mark landstation locations and arrows cross points with other profiles.

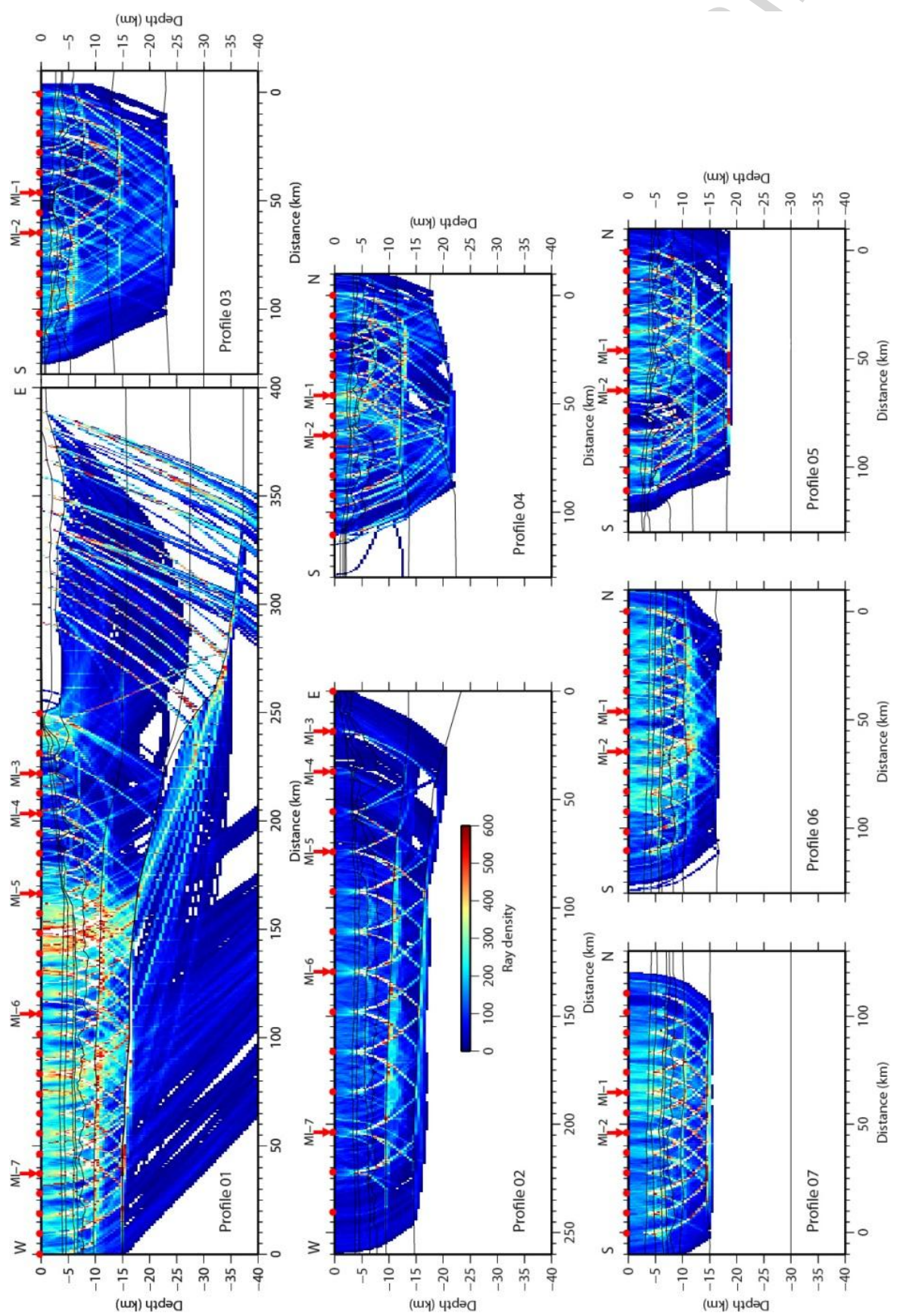



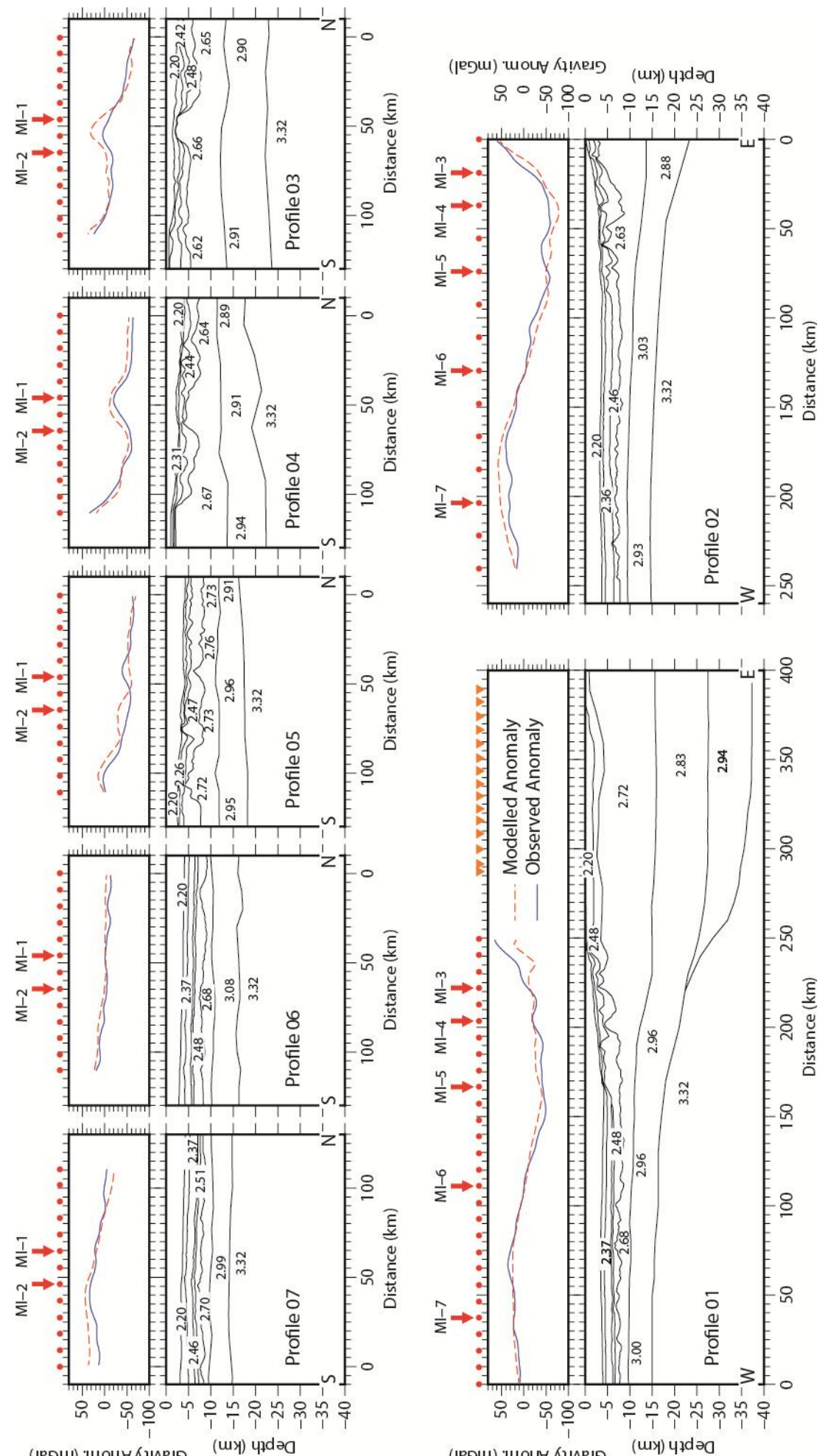

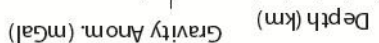

Fig.10: Results from gravity modeling. Positions of OBSs (circles) and landstations (triangles) are indicated. Profil crossings are marked by red arrows. Lower Panels: final velocity models Black line indicates layer boundaries from seismic modeling and stippled lines iso-velocity contours of the final models. Upper panels: modelled (red line) and predicted anomalies (blue lines). 


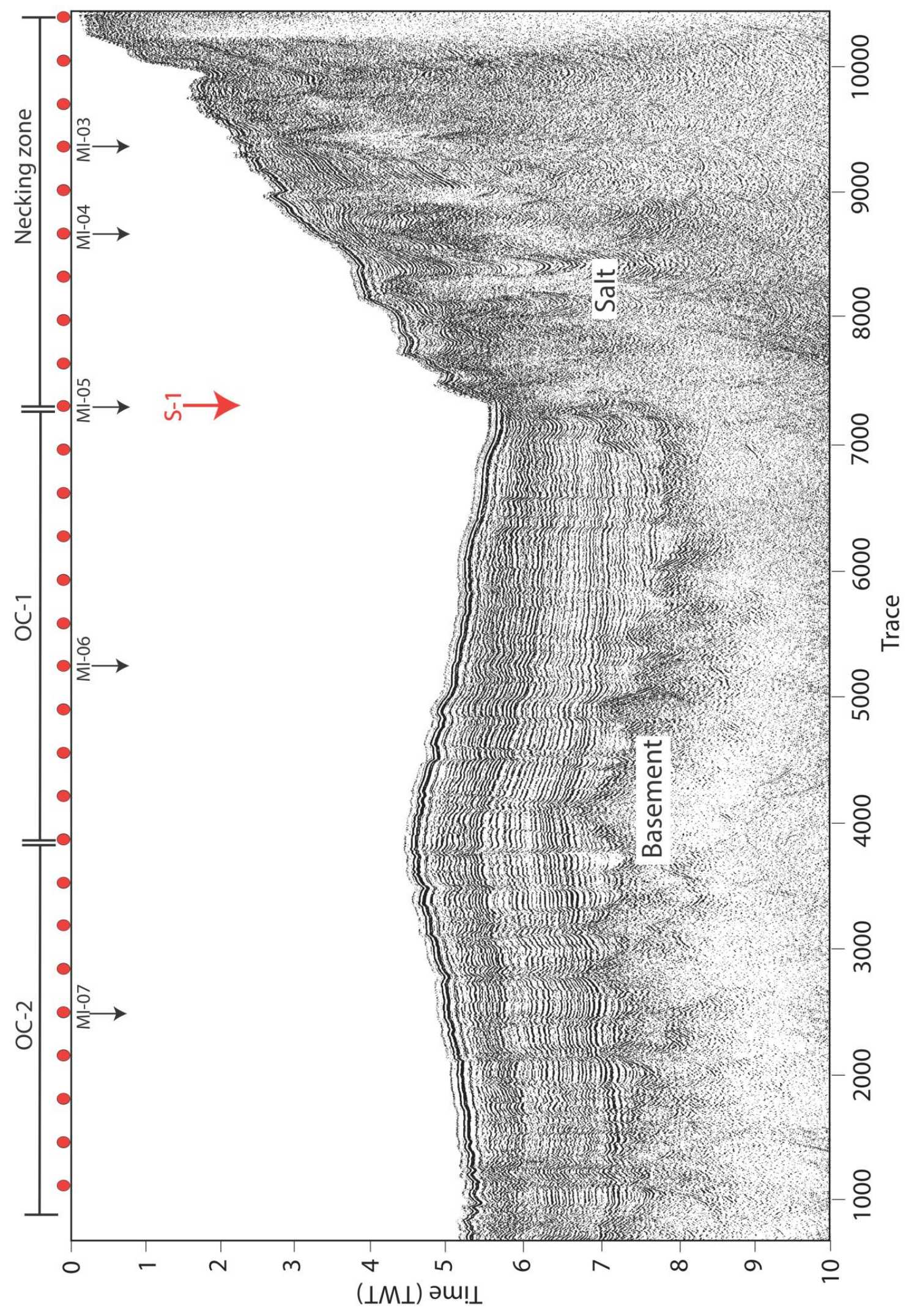

Fig.11: Seismic reflection line-MI-01. OBS locations are indicated by red circles and positions of the magnetic anomaly are indicated by red arrow. Profil crossings are marked by black arrows. 

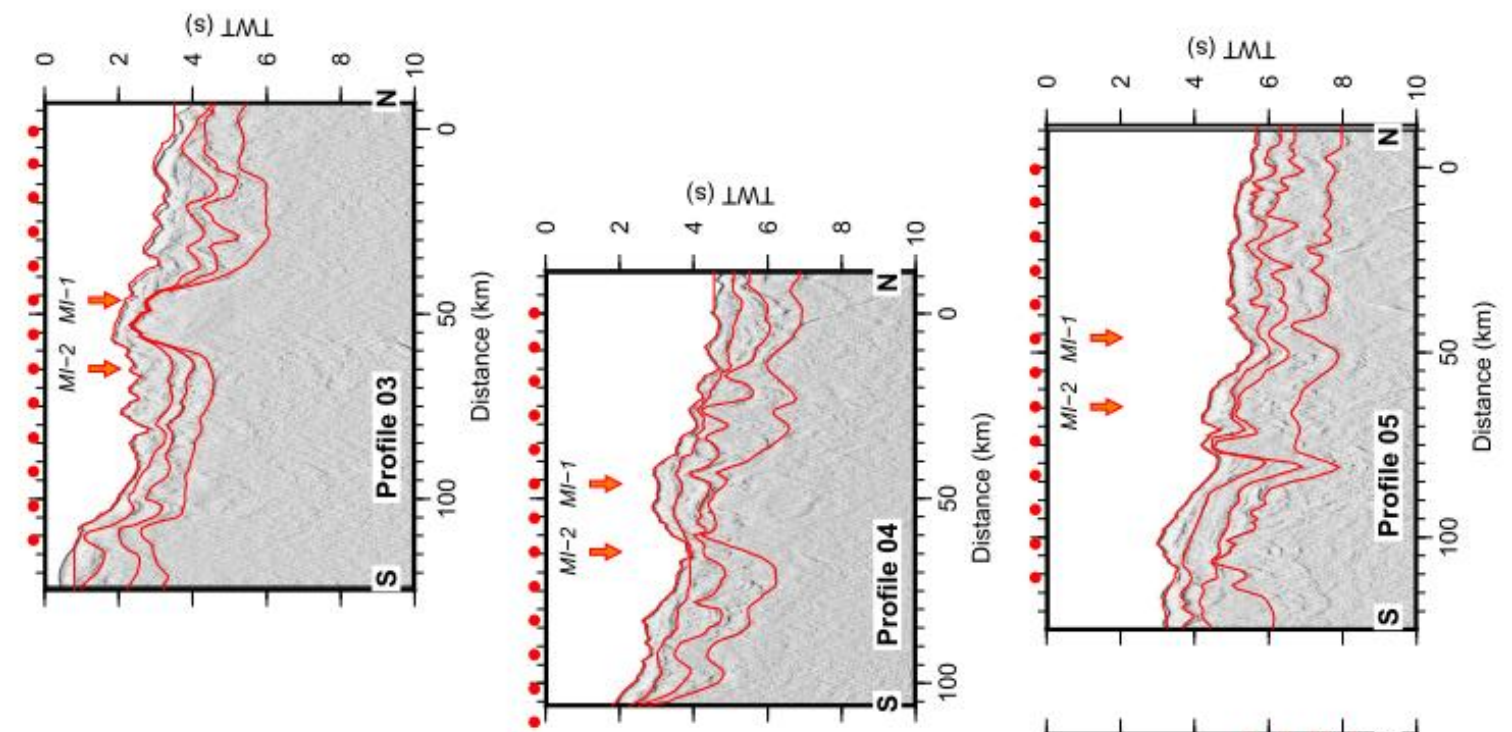

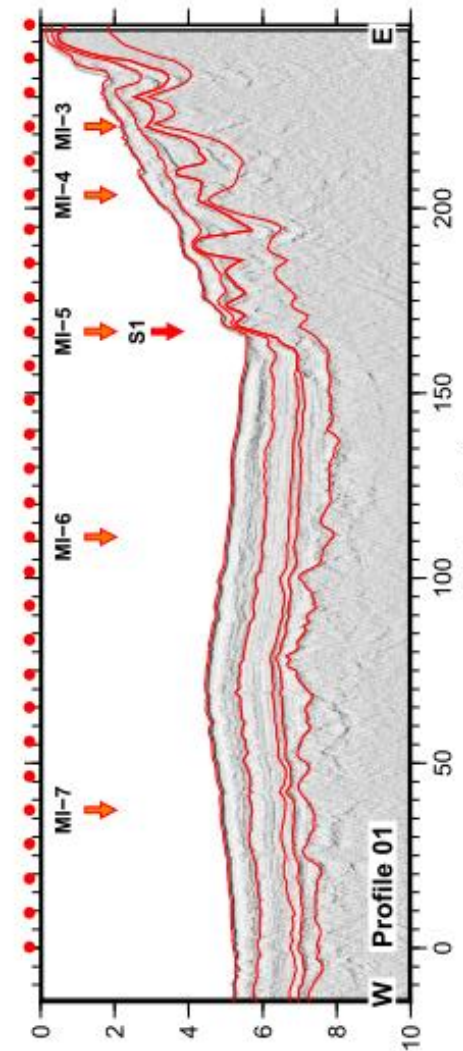

(s) $\perp M \perp$

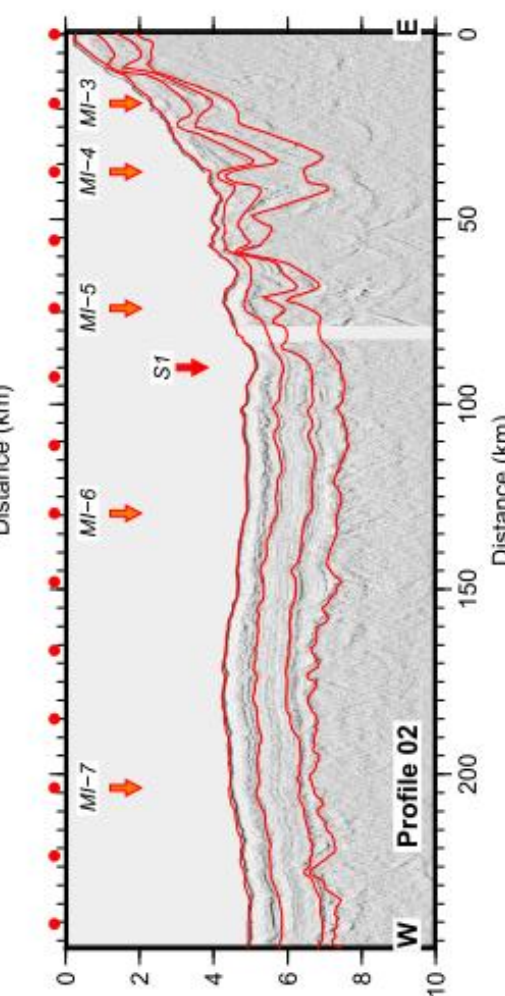

(s) $\perp M \perp$

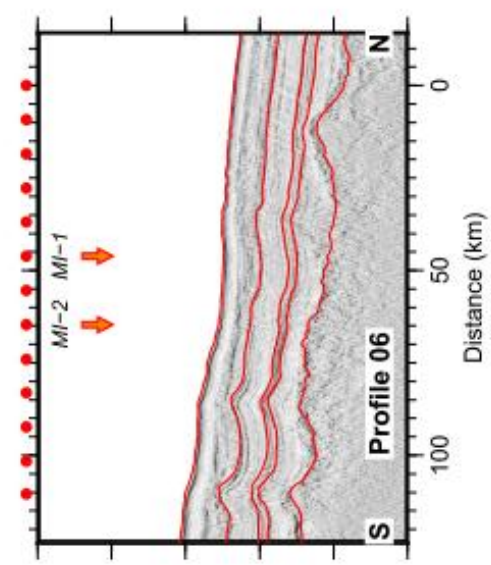

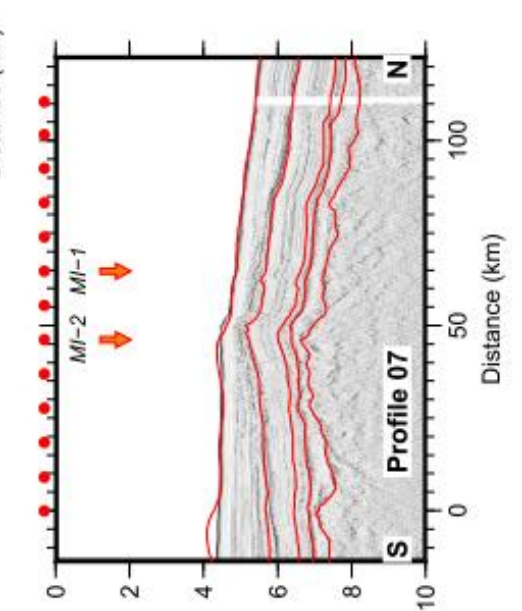

(s) $\perp M \perp$

Fig.12: Reflection seismic sections for all seven Profiles. Model boundaries from wide-angle modeling converted to two-way travel-time are overlain. OBS locations are indicated by red circles and positions of the magnetic anomaly are indicated by red arrow. 


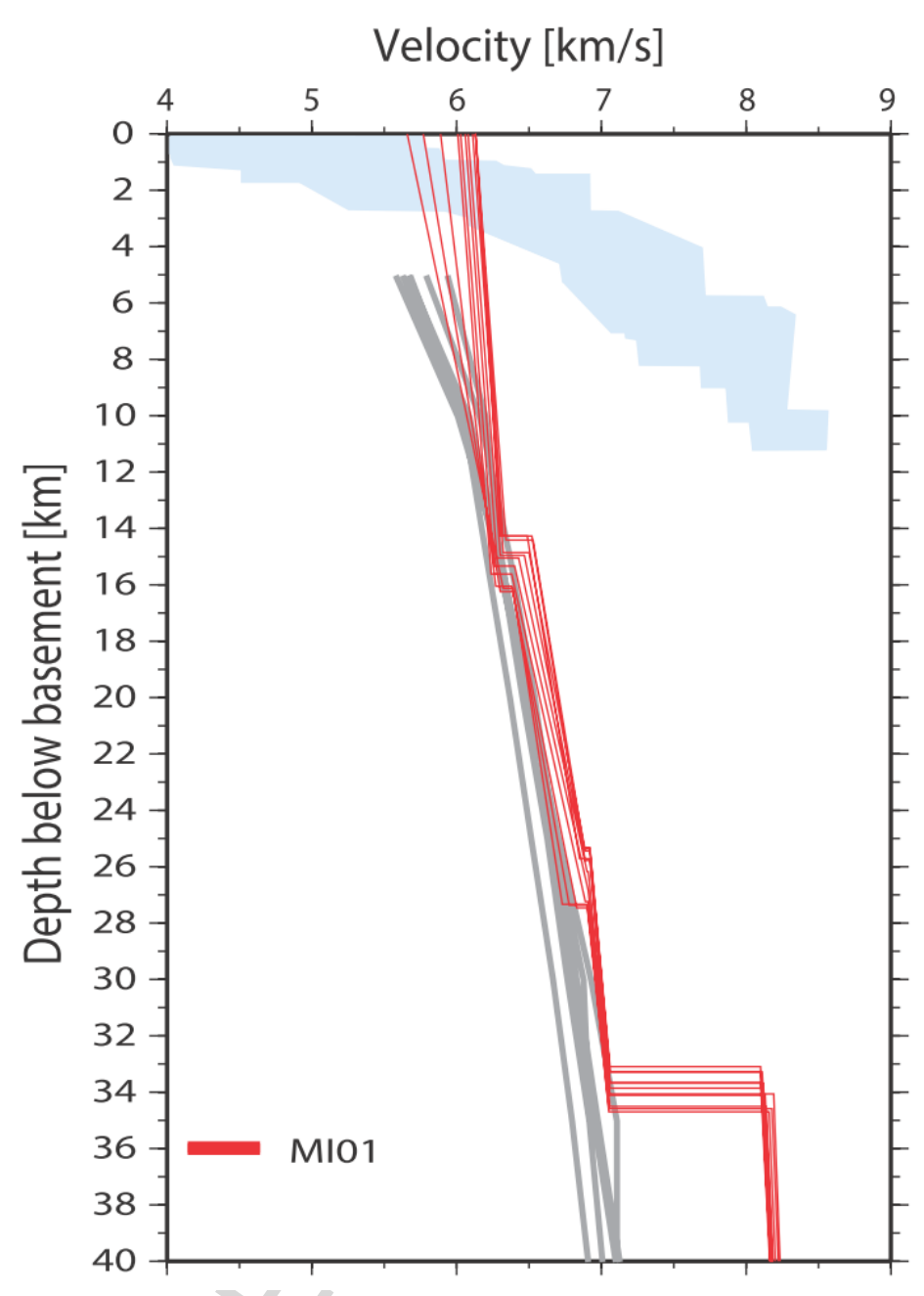

Fig.13: Compilation of 1D velocity-depth profiles extracted below the top of the basement (vz) in the domains of unthinned continental crust. Colored lines mark individual vz-profiles at a $10 \mathrm{~km}$ interval of profile MI-01 ( 270 to $350 \mathrm{~km}$ ). The blue shaded area bounds a compilation of velocity profiles for typical Atlantic oceanic crust (White et al., 1992), and thick dark grey profiles correspond to averaged velocity profiles for continental crust (Christensen and Mooney, 1995). 

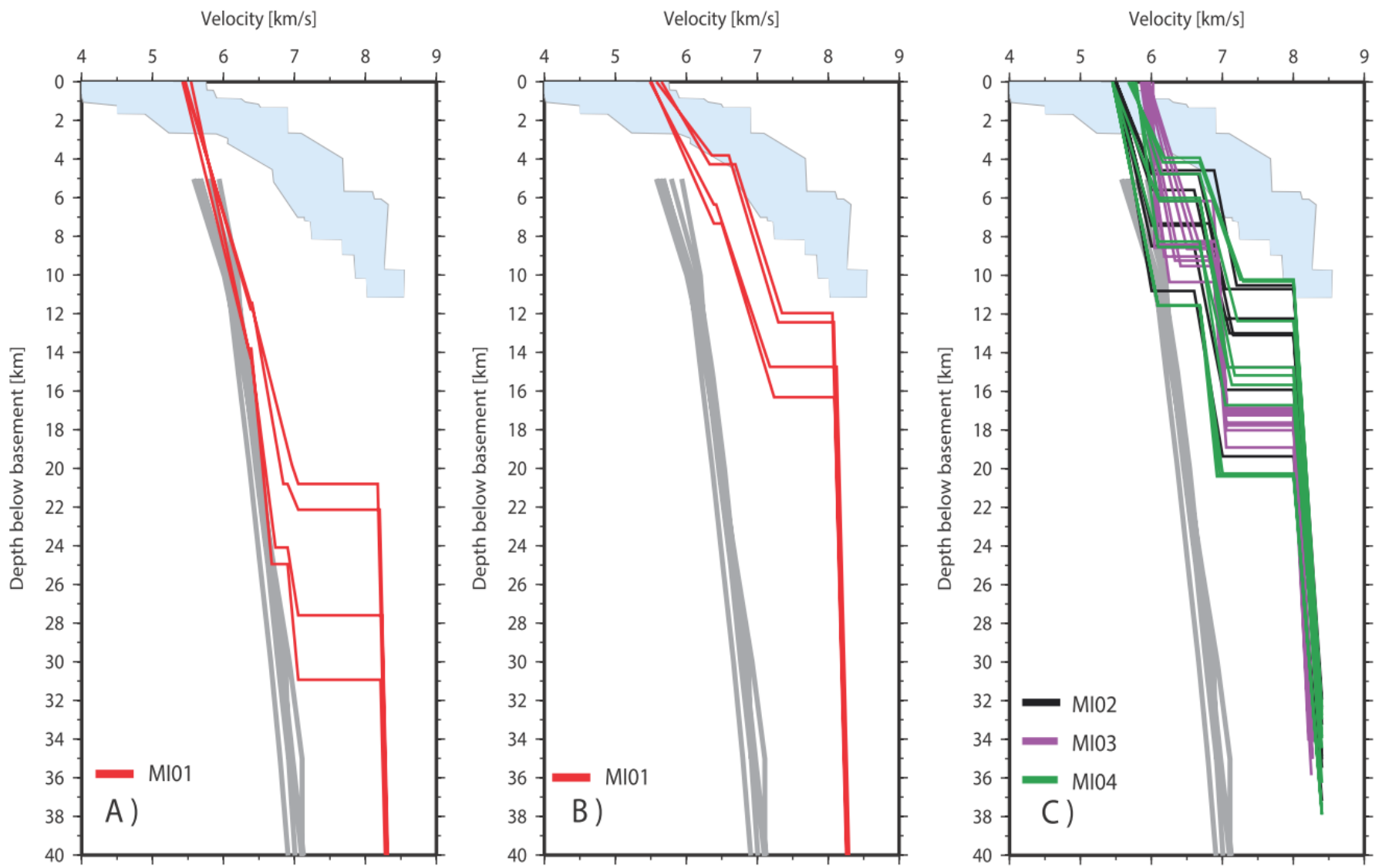

Fig.14: Compilation of 1D velocity-depth profiles extracted below the top of the basement ( $\mathrm{vz}$ ) in the thinning continental crust subdomain 1 and 2. Colored lines mark individual vz-profiles at a $10 \mathrm{~km}$ interval. The blue shaded area bounds a compilation of velocity profiles for the Atlantic oceanic crust (White et al., 1992), while thick dark grey profiles correspond to averaged velocity profiles for continental crust (Christensen and Mooney, 1995). (A) Vz-profiles of profile MI-01 in the thinning subdomain 1 (230 to $260 \mathrm{~km}$ ). (B) Vz-profile of profile MI01 in thinning subdomain $2(180-210 \mathrm{~km})$. (C) Vz-profiles in thinning subdomain 2 of profiles MI-02 (10-70 km), MI-03 and MI-04. 


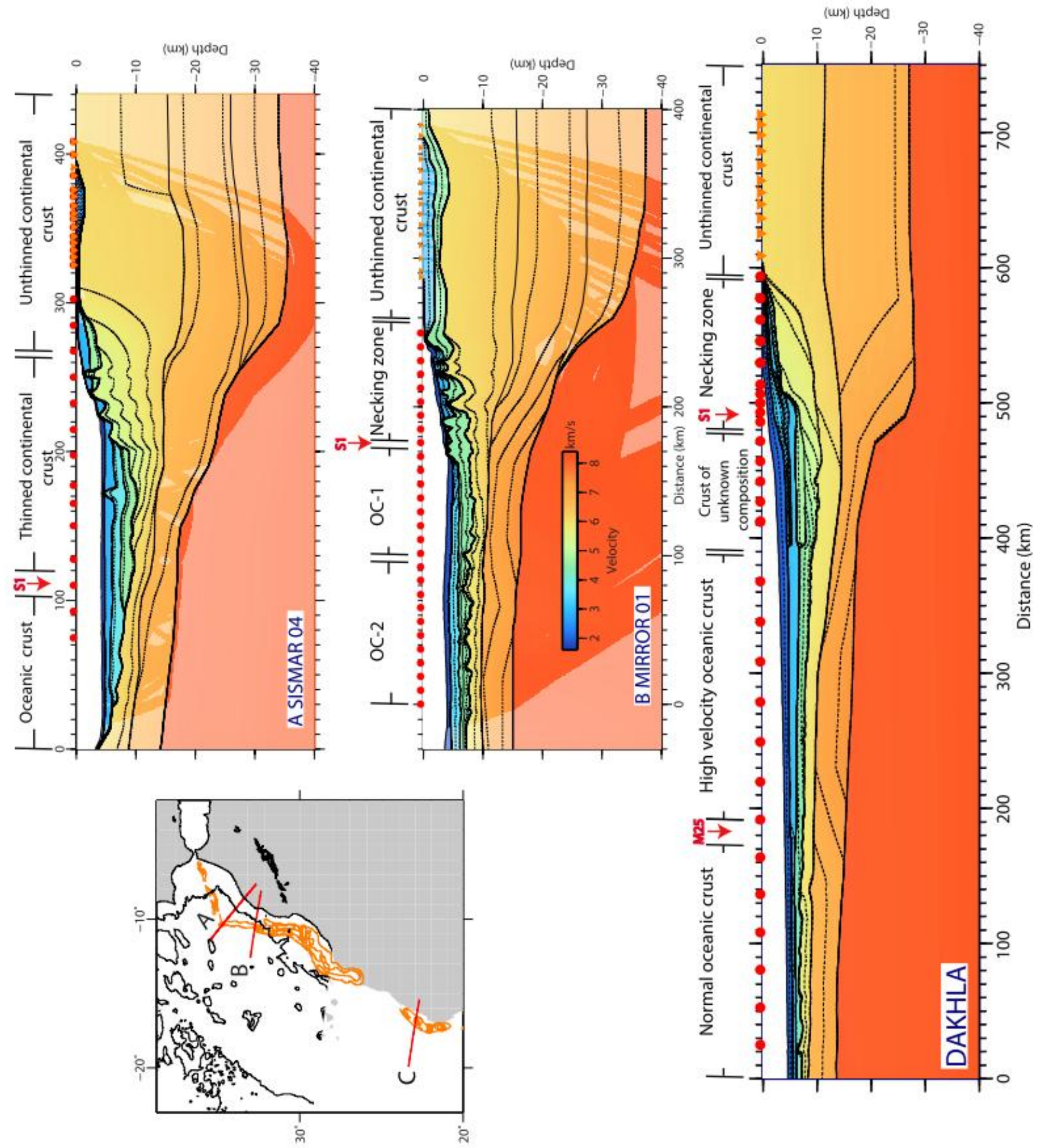

Fig. 15: velocity models for profile perpendicular to the margin from (A) the Sismar cruise (Contrucci et al., 2004) (B) the Mirror cruise (this study) and (C) the Dakhla cruise (Klingelhoefer et al., 2009). OBS positions are indicated by red circles and landstations by orange inverted triangles. The positionsof the magnetic anomalies are indicated by red arrows. 


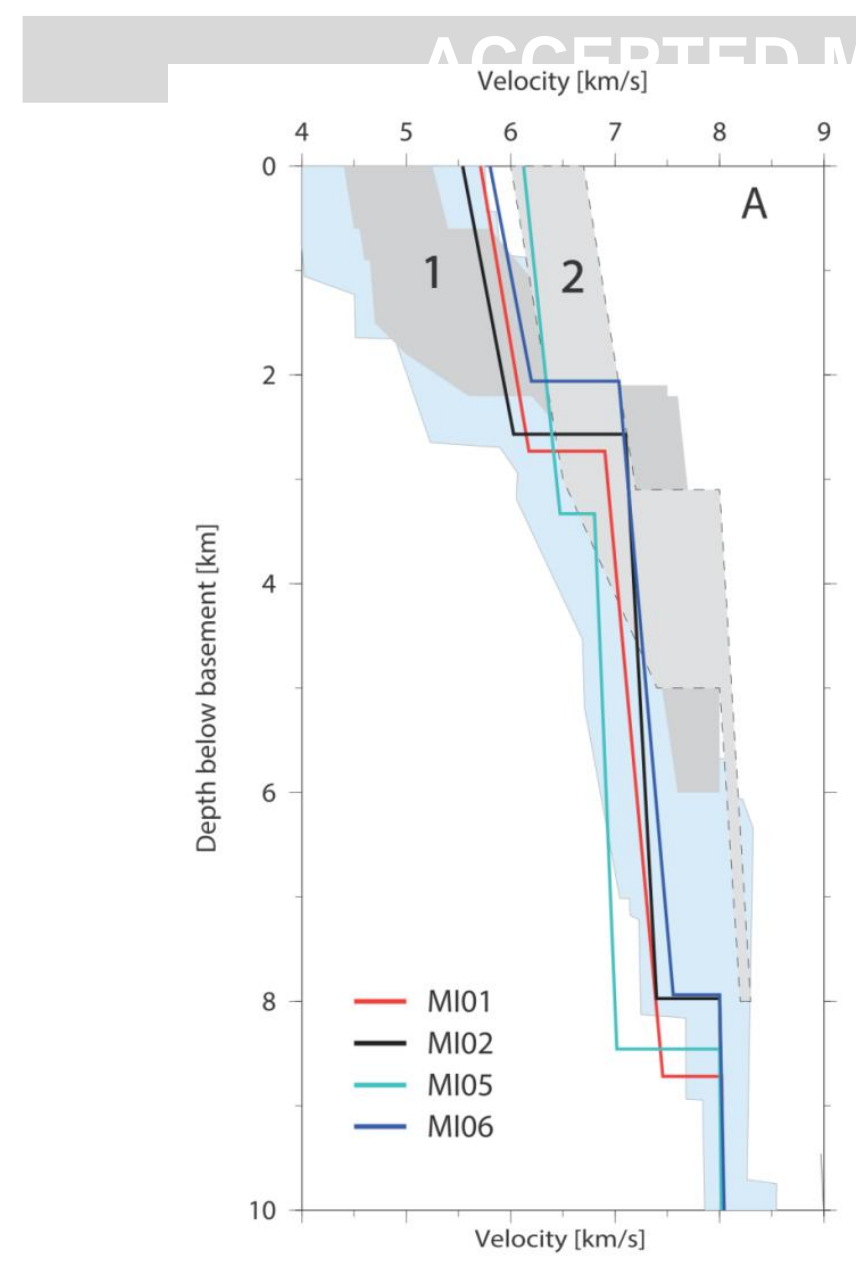

Velocity $[\mathrm{km} / \mathrm{s}]$
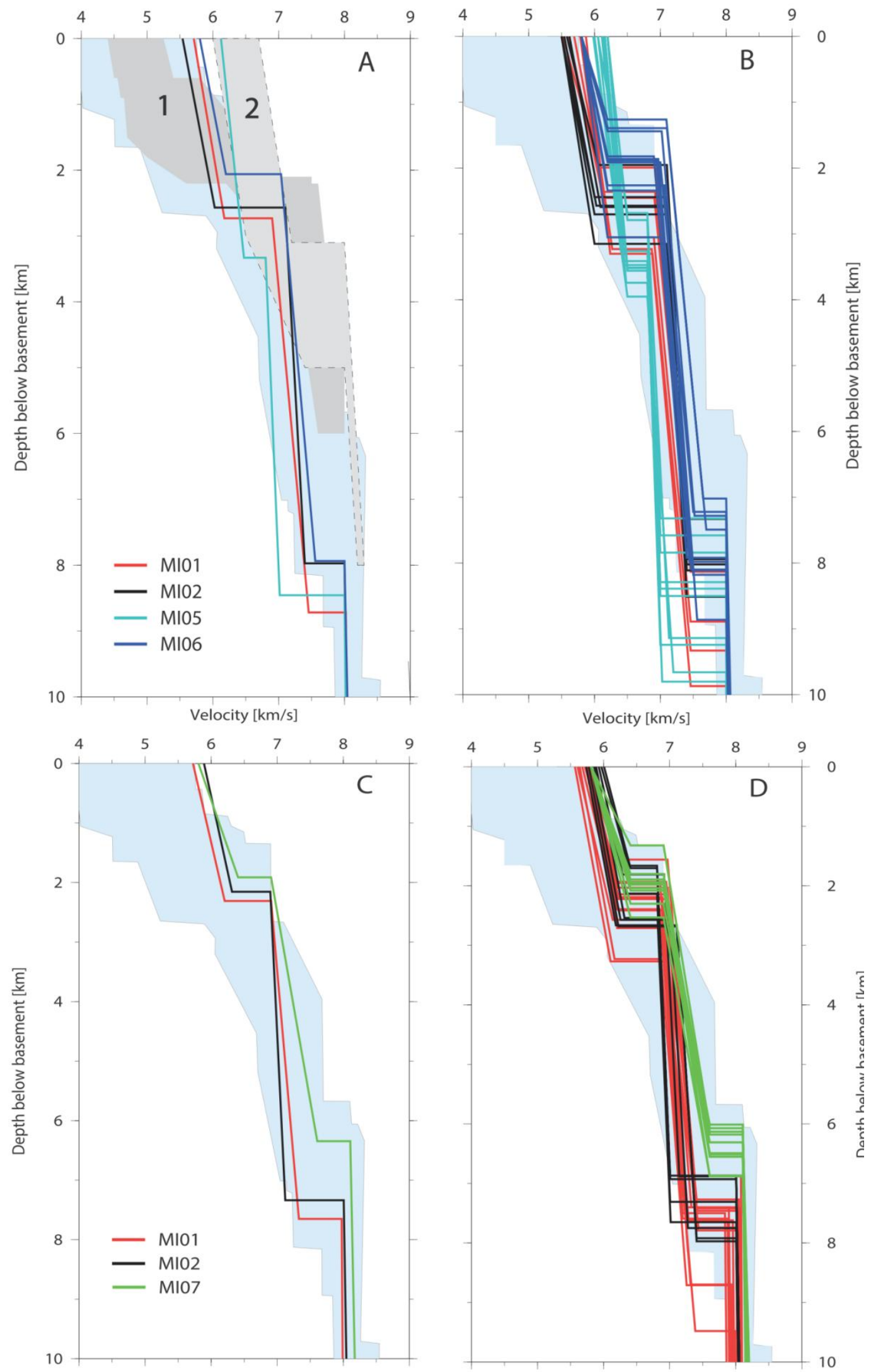

Fig.16: (A) Comparison between a compilation of 1D velocity depth (vz) profiles extracted below the top of the basement in domain OC-1 of MI-01 (80-170 km), MI-02 (80-150 km), MI-05 and MI-06, and the bounds of vz-profiles (light grey areas) from wide-angle seismic models where ocean-continent transition zones was interpreted to be exhumed and/or serpentinised upper mantle: (1) IAM9 in Iberia Abyssal Plain (Dean et al., 2000); (2) SCREECH line 2 in the Grand Banks margin offshore Newfoundland (Van Avendonk et al., 2006). The blue shaded area bounds a compilation of velocity profiles for the Atlantic oceanic crust (White et al., 1992), (B) 1D velocity versus depth below basement (vz) profiles in Domain OC-1 of MI-01 (80-170 km), MI-02 (80-150 km), MI-05 and MI-06 at a $10 \mathrm{~km}$ interval. Note that the vertical scale represent only the first $10 \mathrm{~km}$ of the vertical scale used in the previous figures $13 \& 14$. (C) velocity-depth (vz) profiles extracted below the top of the basement along MI-01 (10-90 km), MI-02 (160-260 km), and MI-07. The blue shaded area bounds a compilation of velocity profiles for the Atlantic oceanic crust (White et al., 1992). (D) 1D velocity-depth below basement (vz) profiles at a $10 \mathrm{~km}$ interval domain OC-2 of MI-01, MI-02, and MI-07. 


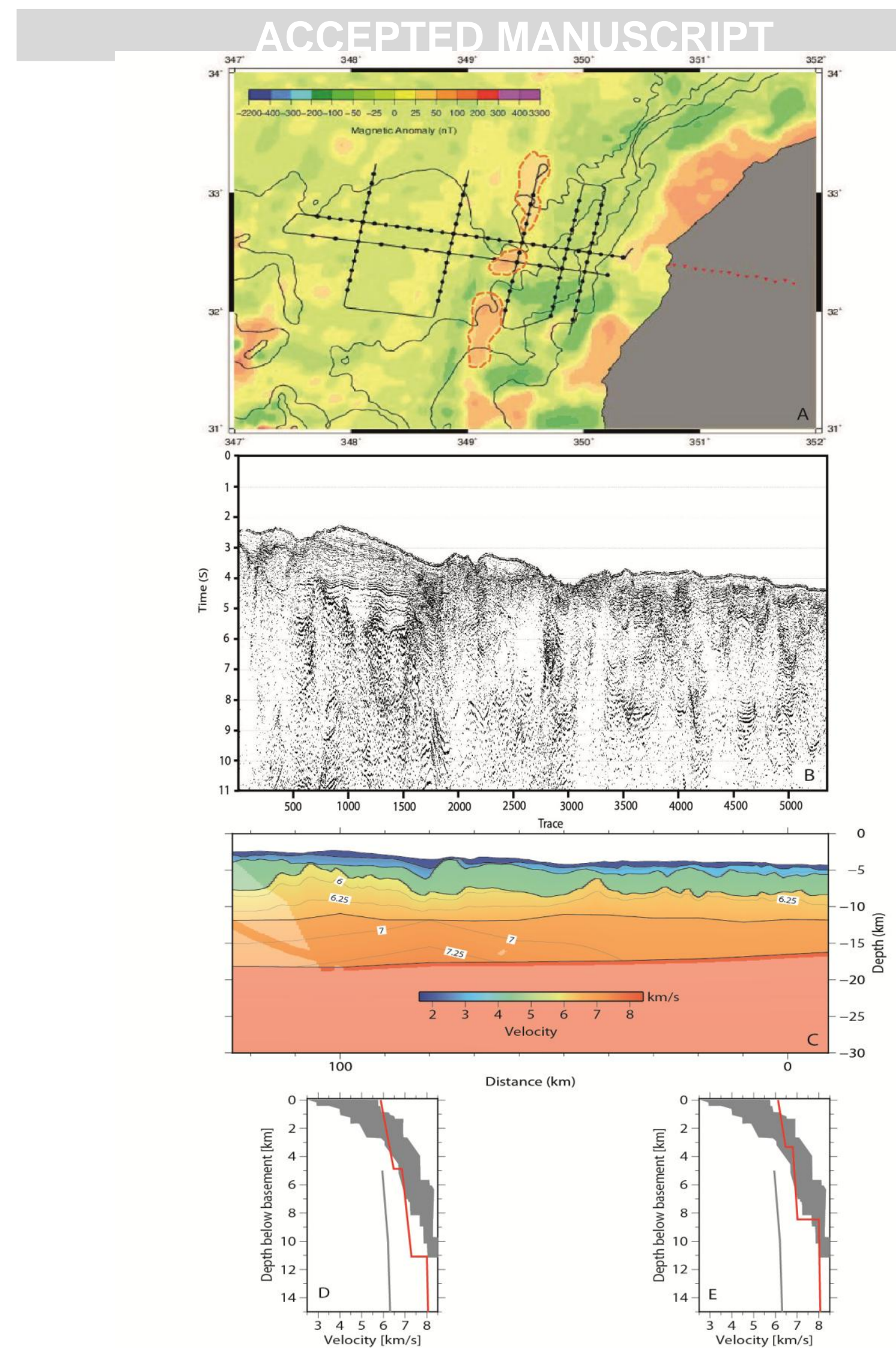

Fig.17: (A) Map of the magnetic anomaly of the study area (Verhoef et al., 1996). Ocean bottom seismometer (OBS) positions are marked by black circles and those of the land stations by red triangles. The multi-channel seismic profiles are indicated by black lines. Positions of the magnetic anomaly are indicating by orange polygons. (B) Reflection seismic sections for MI-05 Profile (C) Mirror Profile 5 final velocity model; (D \& E) 1D velocity versus depth below basement (vz) profiles, the dark grey area bounds a compilation of velocity profiles for the Atlantic oceanic crust (White et al., 1992), thick dark grey profiles correspond to averaged velocity profiles for continental crust (Christensen and Mooney, 1995). 